\title{
Breeding and biotechnological interventions for trait improvement: status and prospects
}

\author{
Roshan Kumar Singh ${ }^{1} \cdot$ Ashish Prasad ${ }^{1} \cdot$ Mehanathan Muthamilarasan $^{2} \cdot$ Swarup K. Parida $^{1} \cdot$ Manoj Prasad $^{1}$ (i)
}

Received: 25 May 2020 / Accepted: 12 September 2020 / Published online: 18 September 2020

(c) Springer-Verlag GmbH Germany, part of Springer Nature 2020

\begin{abstract}
Main conclusion Present review describes the molecular tools and strategies deployed in the trait discovery and improvement of major crops. The prospects and challenges associated with these approaches are discussed.
\end{abstract}

\begin{abstract}
Crop improvement relies on modulating the genes and genomic regions underlying key traits, either directly or indirectly. Direct approaches include overexpression, RNA interference, genome editing, etc., while breeding majorly constitutes the indirect approach. With the advent of latest tools and technologies, these strategies could hasten the improvement of crop species. Next-generation sequencing, high-throughput genotyping, precision editing, use of space technology for accelerated growth, etc. had provided a new dimension to crop improvement programmes that work towards delivering better varieties to cope up with the challenges. Also, studies have widened from understanding the response of plants to single stress to combined stress, which provides insights into the molecular mechanisms regulating tolerance to more than one stress at a given point of time. Altogether, next-generation genetics and genomics had made tremendous progress in delivering improved varieties; however, the scope still exists to expand its horizon to other species that remain underutilized. In this context, the present review systematically analyses the different genomics approaches that are deployed for trait discovery and improvement in major species that could serve as a roadmap for executing similar strategies in other crop species. The application, pros, and cons, and scope for improvement of each approach have been discussed with examples, and altogether, the review provides comprehensive coverage on the advances in genomics to meet the ever-growing demands for agricultural produce.
\end{abstract}

Keywords Molecular markers $\cdot$ Genomics-assisted breeding $\cdot$ Speed breeding $\cdot$ Transgenics $\cdot$ RNA interference $\cdot$ Gene editing

Communicated by Gerhard Leubner.

Roshan Kumar Singh and Ashish Prasad contributed equally.

Electronic supplementary material The online version of this article (https://doi.org/10.1007/s00425-020-03465-4) contains supplementary material, which is available to authorized users.

Manoj Prasad

manoj_prasad@nipgr.ac.in

1 National Institute of Plant Genome Research, Aruna Asaf Ali Marg, New Delhi 110067, India

2 Department of Plant Sciences, School of Life Sciences, University of Hyderabad, Hyderabad, Telangana 500046, India

\section{Introduction}

The human population is growing at a tremendous rate, and it is projected to reach 10 billion by 2050 . This necessitates the need to produce enough grains to meet the food and nutritional security. Thus, agriculture holds the key to meet the needs of the ever-growing population. However, various factors, including challenges associated with the availability of water and irrigation systems, deteriorating soil fertility, erroneous rainfall, rise in atmospheric temperature and heatwaves, insect pests and pathogens, and their evolution to form highly virulent strains, leaves a heavy toll on agricultural productivity. For example, extreme heat and frequent droughts have resulted in about a $10 \%$ reduction in yield of cereal crops throughout the world from 1964 to 2007. The damage had been more in developed countries with an 8-11\% higher loss than developing countries (Lesk et al. 
2016). On the other hand, intensification of crop improvement programmes using biotechnological and breeding interventions had resulted in the trait discovery and release of improved varieties that could mitigate the adverse effects (Fig. 1). Conventional breeding transformed into molecular breeding, which then took the shape of genomics-assisted breeding to meet the challenges in agriculture. Similarly, gene cloning and overexpression or knockout/down diversified to different approaches, including RNAi, VIGS, gene/ genome editing, to develop lines with enhanced agronomic as well as climate-resilient traits. Advances in high-throughput genomics strategies at a whole-genome level, including genetic association mapping, map-based cloning, genomic selection, and speed breeding, are also proven useful in improvising genetic gains for expediting the crop improvement processes.

In one or the other way, these approaches contributed to the increase in the yield of staple crops like maize, rice, and wheat (Bailey-Serres et al. 2019). However, there are some drawbacks, mainly due to the asymmetric support in sub-Saharan and other impoverished areas. Also, the lack of investment in underutilized crops and the replacement of fruits and vegetables with grain crops led to a dietary shift from foods rich in macro- and micronutrients to a calorierich diet (Pingali 2012). Achieving nutritional and food security by increasing the production of nutrient-rich fruits, vegetables, cereals, etc. is the call of the hour and a significant challenge for agricultural scientists (Muthamilarasan et al. 2016; Bailey-Serres et al. 2019). While the technologies and approaches for crop improvement get advanced on the one hand, the problems in agriculture and productivity increase on the other, which is majorly due to the changing climate. FAO predicts that crop yields will decline by $25 \%$ by 2050 if we do not address climate change. Also, studies on the effect of combined environmental stresses are limited as compared to studies on individual stresses, which is again a limiting factor. Though it has been repeatedly underlined that the response of plants towards combined stress is unique as compared to individual biotic or abiotic stress, studies in this direction to delineate the molecular machinery underlying such tolerance and extrapolating the information for crop improvement remain largely elusive. While studies in this direction are need of the hour, synergistic application of two or more integrated modern genomic approaches for developing better varieties also gains momentum. Given this, the review enumerates the different genomics approaches being deployed for trait improvement with examples and provides the roadmap for studying the genomic regions regulating any trait and harnessing the information for an expedited improvement and release of elite varieties.

\section{Genomic resources for trait discovery and crop improvement}

\section{Whole-genome sequencing, resequencing and pangenome analysis}

Genome sequencing has provided direct access to the structural and functional aspects of protein-coding genes organized within the chromosomes of any species. Also, genome sequencing provides information about the noncoding elements, including transposons and promoters, that are crucial for understanding evolution and diversification. Identification of upstream regulatory elements of each gene through genome sequencing has also enabled fine-tuning the expression of target genes, and all these are possible due to the advent of NGS approaches. Started with Arabidopsis thaliana (Arabidopsis Genome Initiative 2000), genome sequencing expanded its horizon by including several crops, plants, and tree species. Rice was the first crop to be sequenced (Yu et al. 2002; Goff et al. 2002; International Rice Genome Sequencing Project 2005), followed by maize (Schnable et al. 2009), sorghum (Paterson et al. 2009), and Soybean (Schmutz et al. 2010). Recently, an annotation-grade whole-genome sequence data of wheat

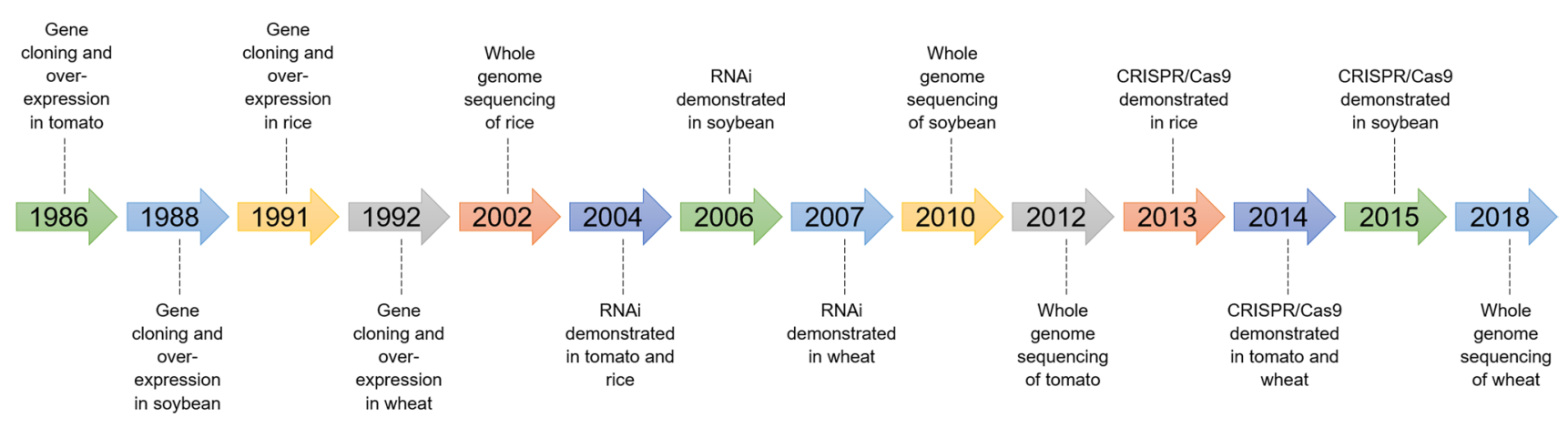

Fig. 1 Timeline of significant achievements in the deployment of approaches, including overexpression of candidate genes, genome sequencing, use of RNAi and genome editing for trait improvement in major species, namely rice, wheat, tomato and soybean 
has been released (International Wheat Genome Sequencing Consortium 2018). In case of foxtail millet, Zhang et al. (2012) had sequenced the genome and reported that around 1500 genes are unique to this crop, where $\sim 580$ are annotated as 'response to water'. Reannotation of these genes provided insights into their classification, wherein a few stress-responsive genes were characterized as genome-wide level (Muthamilarasan and Prasad 2015, 2017a, b). Singh et al. (2019) characterized aquaporin-encoding genes of foxtail millet, and showed that overexpressing SiPIP3;1 and SiSIP1;1 in heterologous yeast system provides tolerance to dehydration and salt stress. Recently, Sood et al. (2020) had optimized the transformation procedure of foxtail millet using Agrobacterium tumefaciens as a medium, and this would enable the overexpression of candidate genes in the crop per se, which would contribute to trait improvement. The decoding of genome sequences of diverse major food crops provides useful genomic information related to structural, functional and comparative genomics for novel trait discovery and genetic enhancement of these crops. Resequencing of germplasms enables the integrated genomics approach of sequence information to identify novel quantitative trait loci (QTLs), genes as well as SNPs that regulate any specific agronomic trait. Significant efforts in this regard have been made in case of rice by sequencing of its 3000 diverse accessions belonging to different populations (Wang et al. 2018). Resequencing of 429 accessions of chickpea is one of the large-scale exercises conducted to determine the candidate genes underlying thirteen traits (Varshney et al. 2019). In this context, the concept of pangenome has gained significant attention, which includes the complete genetic information available within the accessions of the species (Hurgobin and Edwards 2017). Reference genome, together with the resequencing data of all available accessions of a given species, have the considerable potential to expedite molecular breeding as it deploys the entire genetic diversity existing in the species. Development of pangenomes for crop species has been carried out in several plants, such as rice (Schatz et al. 2014; Zhao et al. 2018; Zhou et al. 2020), maize (Hirsch et al. 2014; Xu et al. 2014), soybean (Lam et al. 2010; Li et al. 2014; Liu et al. 2020a, b) and Brassica (Golicz et al. 2016a; Bayer et al. 2019). The quality of the reference assembly determines the appliance of plant pangenomics in terms of size, completeness and annotation, selection, and dense phenotyping of appropriate genotypes (Golicz et al. 2016b). Weckwerth et al. (2020) had underlined the future of pangenomics in enhancing the accuracy for marker-dependent trait performance, increasing the resolution of markers, and combining this approach with other next-generation strategies for accelerating the crop improvement programmes. The application of pangenome instead of single genome sequence as a reference would allow us to determine the retention or loss of valuable genes due to breeding and artificial selection in cultivars. It will further expedite the exploitation of crop wild relatives as well as cultivated accessions/species to improve abiotic and biotic stress tolerance, nutritional properties, architecture, and other economically significant traits in popularly grown cultivars.

Genomics includes the analysis of gene function, their regulation, and inter-networking for association with biological traits. In the field of crop science, comparative functional genomics and transcriptomics are primarily focused on the identification of allelic variations responsible for the improved phenotype. Condition-specific transcriptional activation of a large number of functional and regulatory genes is measured through micro- and macroarrays, quantitative PCR (qPCR), massively parallel signature sequencing (MPSS), serial analysis of gene expression (SAGE) and NGS-based RNA sequencing (RNA-seq) techniques. Global transcriptome profiling in diverse tissues and developmental stages of different crop accessions has led to the generation of Atlas rich in differentially regulated transcripts/ genes indicating complex developmental intricacies in crops (Ref). Global transcriptomic resources may be utilized for an integrative genomics evaluation to delineate the function of genes (Muthamilarasan et al. 2014; Singh and Prasad 2017; Azodi et al. 2020). For example, genome-wide RNA-seq analysis of two contrasting sorghum genotypes: IS20351 (drought-sensitive) and IS22330 (drought tolerant) explored the correlation between physiological response to drought stress and differential gene expression (Fracasso et al. 2016). The abundance of drought-related transcripts was more in the drought-sensitive genotype. A total of 1036 up- and 809 down-regulated genes were identified under drought conditions, among which, 428 and 393 were exclusively up- and down-regulated in the tolerant genotype, respectively. The study revealed the different strategies adopted by both the genotypes in coping with drought conditions. The tolerant IS22330 genotype initiated the synthesis of secondary metabolites, including glycinbetaine and glutathione, whereas sensitive IS20351 genotype hydrolyzed carbohydrates and sugars. Therefore, the extent of drought imposition and perception was more in susceptible genotype than the tolerant. The tolerant genotype could be used as a genetic donor in sorghum germplasm improvement related to drought tolerance traits. Similarly, global transcriptome analysis in response to high temperature and drought has identified 29,395 differentially expressed genes (DEGs) in wheat (Liu et al. 2015), 696 and 808 DEGs under low- and high-nitrogen conditions in rice (Xin et al. 2019), 267 and 1421 DEGs under short- and long-term hypoxia in tomato roots (Safavi-Rizi et al. 2020) and various other crops under different conditions. The DEGs are being functionally characterized and utilized in crop improvement through breeding, genetic engineering, or genome editing. 


\section{Development and deployment of molecular markers for breeding and allied research}

Molecular markers form the backbone of classical genetics and plant breeding as it enables selection and breeding for any given trait. Development of molecular markers, construction of genetic linkage maps, mapping of QTLs, saturation of maps, and fine mapping of the precise gene were once time-consuming and labour-intensive processes. However, the advent of next-generation sequencing (NGS) has enabled the development of large-scale molecular markers, including microsatellite or simple sequence repeat (SSR), insertion-deletions (InDels), and single nucleotide polymorphisms (SNP). These markers enabled the development of high-density genetic maps useful for mapping of target genes and utilize them in crop breeding. Molecular markers are also employed for the detection of genetic variation associated with valuable agronomic traits among cultivars in a species and facilitate the identification of appropriate parents for molecular breeding. They further ease the selection of desirable offspring resulted from the parental cross at the early stage of their development. Genome-wide marker analysis in Chinese spring wheat has led to the identification of 364,347 SSR markers from 10,603,760 sequences of the genome with $36.68 \mathrm{SSR}$ markers/Mb density (Han et al. 2015). A total of 488 forms of SSR motifs were detected with a maximum proportion of dinucleotide repeats $(42.52 \%)$, followed by a trinucleotide $(24.94 \%)$, hexanucleotide $(24.65 \%)$, tetranucleotide $(4.62 \%)$ and pentanucleotide $(3.25 \%)$ in the genome. AG/CT, AAG/ CTT, AGAT/ATCT, AAAAG/CTTTT, and AAAATT/ AATTTT remained the most abundant repeats of di- to hexanucleotide SSR motifs. Similarly, in foxtail millet, genome-wide 28,324 microsatellite-repeat motifs have been identified covering 405.3 $\mathrm{Mb}$ of the whole-genome sequence (Pandey et al. 2013). The abundance of trinucleotide repeats $(48 \%)$ was more in this case than the dinucleotide repeats (46\%). In barley, Zhou et al. (2015) have identified 436,640 InDels throughout the genome after aligning the DNA sequences from two different accessions-Morex and Barke. Among these $1140 \mathrm{InDel}$ markers were integrated with 383 SSRs, 1544 DarT (diversity arrays technology), and 3909 gene-based SNP markers into a single barley genetic map. In addition to these, the development of other classes of markers such as transposable element-based and miRNA-based markers was demonstrated in different crops, including foxtail millet (Muthamilarasan and Prasad 2015). These markers were proven useful in large-scale genotyping applications in millets, cereals, and bioenergy grass species. Their application has also been extended to evolutionary studies and phylogenetic relationships, genetic diversity analysis, map-based cloning, and DNA-fingerprinting. Garrido-Cardenas et al. (2018) has exquisitely described the applications and trends of molecular markers research in the field of plant science.

Single nucleotide polymorphism is another critical class of molecular marker abundantly distributed in the genome and detected through a comparative study of whole-genome sequence or transcriptome data of different accessions or genotypes (Habash et al. 2009). Advancements in NGS technologies with simultaneous reduction of their cost have prompt the detection and utilization of large-scale SNP marker for crop improvement. Approximately 20 million SNPs from rice were identified after aligning the reads from 3000 genome sequences with the Nipponbare genome as reference (Alexandrov et al. 2015). In wheat, 46,977 geneassociated SNPs from 90,000 high-density SNP array were genetically mapped using the combination of eight mapping population (Wang et al. 2014). In total, 6,385,011 SNP with high density were identified from 15 different droughtresponsive inbred maize lines and $\mathrm{B} 73$ reference genome (Xu et al. 2014). The abundance of SNPs was more in the intergenic region (approximately 85\%) and intronic (7.67\%) region followed by upstream, exon, UTR, and splice sites. 271 non-synonymous SNP (nsSNPs)-associated candidate genes responsible for drought tolerance were also revealed (Xu et al. 2014). Resequencing of 588 Brassica napus accessions from 21 countries has generated about 5,294,158 SNPs and 1,307,151 indels. Through genome-wide association study (GWAS), 60 loci significantly associated with agronomic traits such as oil content, seed quality, stress tolerance were identified, which may be proven as a valuable resource for genetic improvement ( $\mathrm{Lu}$ et al. 2019). The study also revealed the origin of B. napus from the hybridization between domesticated Brassica rapa and Brassica oleracea approximately 1910-7180 years back. These genetic resources have enormous significance in diversity studies and understanding the genetic basis of trait variation throughout the population. The genome and transcript sequences available for diverse crops have led to the generation of numerous genomic and genetic sequence-based markers like SSRs, SNPs, and InDels for their further use in genomics-assisted crop improvement. These markers are found efficient in rapid large-scale genotyping among natural germplasm accessions and bi-parental mapping populations through association and QTL mapping for trait discovery in crops.

\section{QTLs associated with agronomic traits}

The analysis of quantitative trait locus (QTL) is a statistical approach that correlates the phenotypic measurements with the genotypic data to evaluate the genetic basis of variations among complex traits. The pipeline for QTL mapping 
requires a mapping population segregating for understudied agricultural traits, precise phenotyping, development of large scale high throughput genomic markers, construction of genetic map through genotyping of mapping population with polymorphic genomic markers and finally mapping of QTL utilizing both phenotypic and genotypic data (Mir et al. 2012). The biparental mapping population used for QTL mining is either of $\mathrm{F}_{2}$, double haploids, backcrosses, nearisogenic lines (NILs), or recombinant inbred lines (RILs). This approach of linkage analysis-based QTL mapping was used thoroughly during the last decade for various crops. However, this process encompasses several limitations, as illustrated by Myles et al. (2009); therefore, to overcome the constraints, linkage disequilibrium (LD)-based association mapping was introduced to map QTLs for dissecting complex agronomically significant traits (Singh et al. 2017). The advantages of association mapping over bi-parental linkage mapping are (1) superior mapping resolution through the exploration and utilization of each recombination event that happened in the evolutionary history of the species, (2) use of natural germplasm collection rather than the development of specialized mapping population, (3) less time consuming and cost-effective, (4) use of same association mapping panel and genotyping data for mapping other traits and (5) larger number of alleles can be mined compared to the linkage analysis-based QTL mapping where only two alleles are usually sampled (Mir et al. 2012). With the availability of crop genetic and genomic resources, genome-wide association study (GWAS), candidate gene-based association mapping, QTL mapping, fine mapping, and map-based cloning are becoming popular to discover novel QTLs, genes, and alleles associated with traits of agronomic importance in major food crops. More recently, the Department of Biotechnology (DBT), Government of India, has initiated the genotypic and phenotypic characterization of more than 65,000 germplasm accessions of rice, wheat, minor pulses, and minor oilseeds conserved at National Genebank through GWAS for trait discovery and genetic improvement of these crops.

Multi-parent advanced generation inter-crosses (MAGIC) and nested association mapping (NAM) are specially designed population structures for multi-parent association studies (Ladejobi et al. 2016). For genotyping, restrictionsite associated sequencing (RAD-Seq), genotyping-bysequencing (GBS), skim-sequencing, and whole-genome resequencing approach are being exploited for mid to highdensity trait mapping through QTL-based analysis (Roorkiwal et al. 2020). Molecular markers linked with various agronomic traits derived from association mapping are reported in crops including soybean (Hu et al. 2014), brassica (Qu et al. 2017; Zhu et al. 2019), rice (Feng et al. 2016; Rao et al. 2018), chickpea (Bajaj et al. 2016; Li et al. 2018), foxtail millet (Jaiswal et al. 2019a, b) and various others plants (reviewed by Muthamilarasan et al. 2019). In plants, QTLs were mostly identified for a variety of agronomic traits, including abiotic and biotic stress tolerance, yield and yield contributing factors, flowering time, root architecture and nutrient uptake, and nitrogen fixation (in case of soybean). A few landmark QTLs associated with nutritional traits in major cereal crops (rice, wheat, and maize) are listed in Table 1. In addition to these genomic QTLs, several other types of QTLs, namely expression QTL (eQTL), proteomic QTL (pQTL), metabolic (mQTL), and phenomic QTL (phQTL) are seeing their dawn in breeding for crop improvement. An eQTL illustrates the genetic variance of a gene expression phenotype (Nica and Dermitzakis 2013), while in pQTL, protein abundance is correlated with genetic polymorphism (Rodziewicz et al. 2019). On the other hand, chromosomal regions that encompass loci that contribute to genetic variation in phenotypic traits are called phQTL. The targeted metabolome profiling of wheat kernel through LC-MS/MS followed by linkage analysis has resulted in the identification of 1005 mQTLs distributed unevenly in the genome. Twenty-two candidate genes underlying these mQTLs regulating the level of different metabolites were functionally annotated (Shi et al. 2020). Comprehensive information about these QTLs is essential for facilitating the effective use of genes and genomic regions that regulate key traits. Various modern NGS-driven QTL mapping strategies like bulk population resequencing: QTL-seq, individual population resequencing, and MutMap utilizing bi-parental mapping and mutant populations are found expedient for identification of major QTLs modulating agronomic traits in crop plants. All these advanced genomics, including novel QTL strategies, enabled to detect both major as well as minor QTLs governing gene regulatory networks underlying vital agronomic traits for quantitative dissection of complex traits and further genetic improvement of crops.

\section{Genomics-assisted breeding for trait improvement}

Genomics-assisted breeding (GAB) is initiated with the identification of genomic markers associated with QTL or gene(s) related to the agronomic trait of interest and then their application in the breeding platform (Fig. 2). Molecular markers assist in an assortment of desired offspring in the breeding cycle at the early growth stage utilizing NGSbased high throughput genotyping platforms (Singh et al. 2017; Crossa et al. 2017). Numerous GAB strategies have been deployed for crop improvement, including markerassisted backcrossing, marker-assisted recurrent selection, and genomic selection. Recently, speed breeding is added to the list to expedite breeding processes. Countries like India predominantly rely on breeding for crop improvement and 
Table 1 Summary of major QTLs identified for nutrition-related traits in major cereal crops

\begin{tabular}{|c|c|c|c|c|c|}
\hline Crop & Trait & $\begin{array}{l}\text { No. of QTLs } \\
\text { identified }\end{array}$ & Linkage group & $\begin{array}{l}\text { Phenotypic varia- } \\
\text { tion explained (\%) }\end{array}$ & References \\
\hline \multirow[t]{20}{*}{ Rice } & $\mathrm{Zn}, \mathrm{Se}$ and $\mathrm{Cd}$ accumulation in grains & 5 & $4,5,6$ and 9 & $13.8-16.4$ & Liu et al. (2020a) \\
\hline & $\mathrm{Fe}$ and $\mathrm{Zn}$ concentration in grain & 23 & All accept 4,8 and 11 & $7.18-22.03$ & Calayugan et al. (2020) \\
\hline & Cooking and eating quality of grain & 14 & $1,2,3,4,6,9$ and 10 & $5.33-37.72$ & Park et al. (2019) \\
\hline & Nutrient content and yield & 72 & All except 5 and 10 & $2.3-75.6$ & Kinoshita et al. (2017) \\
\hline & Sugar-related trait in grain & 17 & $1,3,4,5,6$ and 8 & $7.5-18$ & Yang et al. $(2014 a, b)$ \\
\hline & Amylose, protein and lipid content in grain & 8 & $1,2,3,6,8,9$ and 10 & $30.0-40.0$ & Yun et al. (2014) \\
\hline & Macro- and microelements & 139 & All chromosomes & $3.1-12.9$ & Zhang et al. (2014) \\
\hline & Amylose, lipid and protein content of grain & 8 & $2,3,6,7,9$ and 11 & $3.9-19.3$ & Lee et al. (2014) \\
\hline & Lipid content & 1 & 5 & 20.0 & Kim et al. (2013) \\
\hline & Lipid metabolism & 29 & All except 9 and 10 & $7.16-37.93$ & Ying et al. (2012) \\
\hline & Fat content & 2 & 7 & $10.0-18.6$ & Shen et al. (2012) \\
\hline & Grain chalkiness & 3 & 5,8 and 10 & $9.6-25.0$ & Liu et al. (2012) \\
\hline & $\begin{array}{l}\text { Chalkiness, amylose and protein content } \\
\text { and viscosity }\end{array}$ & 132 & All chromosomes & $2.0-68.2$ & Liu et al. (2011) \\
\hline & Mineral content in grain & 31 & All except 7 & $5.0-19.0$ & Garcia-Oliveira et al. (2009) \\
\hline & Viscosity and food quality of grain & 26 & All except 10 & $1.0-88.0$ & Wang et al. (2007) \\
\hline & Phytate and micronutrient content & 11 & $1,2,5,7,8$ and 12 & $12.8-26.5$ & Stangoulis et al. (2007) \\
\hline & Starch synthesis and cooking quality & 7 & 5 and 6 & $11.3-72.8$ & He et al. (2006) \\
\hline & Cooking and eating quality of rice grain & 12 & $1,2,3,6$ and 11 & $8.0-80.3$ & Tian et al. (2005) \\
\hline & Grain quality & 27 & All except 9 & $3.0-73.7$ & Aluko et al. (2004) \\
\hline & Protein and fat content & 5 & $1,2,4,5,6$ and 7 & $5.1-23.0$ & Hu et al. (2004) \\
\hline \multirow[t]{16}{*}{ Wheat } & Gluten strength & 5 & $1 \mathrm{~A}, 1 \mathrm{~B}$ and $3 \mathrm{~A}$ & $3.4-40.1$ & Ruan et al. (2020) \\
\hline & $\begin{array}{l}\text { Gran protein content and thousand kernel } \\
\text { weight }\end{array}$ & 23 & $\begin{array}{l}1 \mathrm{~A}, 1 \mathrm{~B}, 2 \mathrm{~A}, 3 \mathrm{~A}, 4 \mathrm{~A}, 4 \mathrm{~B}, 5 \mathrm{~A}, 6 \mathrm{~A} \\
6 \mathrm{~B} \text { and } 7 \mathrm{~B}\end{array}$ & $0.6-24.4$ & Fatiukha et al. (2020) \\
\hline & Grain protein content and yield & 22 & $\begin{array}{l}1 \mathrm{~B}, 2 \mathrm{~A}, 2 \mathrm{~B}, 3 \mathrm{~A}, 4 \mathrm{~A}, 4 \mathrm{~B}, 4 \mathrm{~B}, 5 \mathrm{~B} \\
7 \mathrm{~A} \text { and } 7 \mathrm{~B}\end{array}$ & $8.0-23.0$ & Giancaspro et al. (2019) \\
\hline & Grain protein content and protein deviation & 17 & $\begin{array}{l}2 \mathrm{~B}, 3 \mathrm{~A}, 3 \mathrm{~B}, 4 \mathrm{~A}, 4 \mathrm{~B}, 5 \mathrm{~A}, 5 \mathrm{~B}, 6 \mathrm{~B} \\
7 \mathrm{~A} \text { and } 7 \mathrm{~B}\end{array}$ & $4.1-8.7$ & Nigro et al. (2019) \\
\hline & $\begin{array}{l}\text { Grain } \mathrm{Fe}, \mathrm{Zn} \text { and protein content and } \\
\text { thousand kernel weight }\end{array}$ & 16 & $\begin{array}{l}1 \mathrm{~A}, 2 \mathrm{~A}, 2 \mathrm{~B}, 3 \mathrm{~A}, 4 \mathrm{~A}, 5 \mathrm{~A}, 5 \mathrm{~B}, 7 \mathrm{~A}, \\
\text { and } 7 \mathrm{~B}\end{array}$ & $2.3-6.8$ & Krishnappa et al. (2017) \\
\hline & $\begin{array}{l}\beta \text {-Glucans and protein content and grain } \\
\text { yield/spike }\end{array}$ & 19 & $\begin{array}{l}1 \mathrm{~B}, 2 \mathrm{~A}, 2 \mathrm{~B}, 3 \mathrm{~A}, 3 \mathrm{~B}, 4 \mathrm{~A}, 5 \mathrm{~A}, 6 \mathrm{~B} \\
7 \mathrm{~A} \text { and } 7 \mathrm{~B}\end{array}$ & - & Marcotuli et al. (2017) \\
\hline & $\mathrm{Fe}$ and $\mathrm{Zn}$ content & 8 & $1 \mathrm{~A}, 2 \mathrm{~A}, 3 \mathrm{D}, 4 \mathrm{~A}, 4 \mathrm{D}, 7 \mathrm{~B}$ and $7 \mathrm{D}$ & $29.1-51.45$ & Roshanzamir et al. (2013) \\
\hline & Starch granule size & 3 & $1 \mathrm{D}, 4 \mathrm{~A}$ and $7 \mathrm{~B}$ & $3.8-5.6$ & Feng et al. (2013) \\
\hline & Protein content & 25 & $\begin{array}{l}1 \mathrm{D}, 2 \mathrm{~A}, 2 \mathrm{~B}, 3 \mathrm{~B}, 4 \mathrm{~A}, 5 \mathrm{~B}, 5 \mathrm{D}, 6 \mathrm{~B} \\
\text { and } 7 \mathrm{~A}\end{array}$ & $4.11-10.90$ & Wang et al. (2012) \\
\hline & Grain water-soluble oligosaccharide & 10 & $\begin{array}{l}1 \mathrm{~B}, 1 \mathrm{D}, 2 \mathrm{~B}, 2 \mathrm{D}, 3 \mathrm{~B}, 4 \mathrm{~A}, 5 \mathrm{~A}, 5 \mathrm{D}, \\
\text { and } 6 \mathrm{~B}\end{array}$ & $6.98-38.30$ & Fu et al. (2011) \\
\hline & Quantity of protein fraction in grain & 55 & $1 \mathrm{~A}, 1 \mathrm{~B}, 1 \mathrm{D}, 3 \mathrm{~A}, 3 \mathrm{~B}, 4 \mathrm{~A}, 5 \mathrm{D}$ and $7 \mathrm{~A}$ & $2.1-73.2$ & Zhang et al. (2011) \\
\hline & Grain protein concentration & 9 & $1 \mathrm{~A}, 1 \mathrm{~B}, 2 \mathrm{~A}, 2 \mathrm{~B}, 5 \mathrm{~B}, 6 \mathrm{~B}, 7 \mathrm{~A}$ and $7 \mathrm{~B}$ & $11.1-17.6$ & Suprayogi et al. (2009) \\
\hline & Protein and mineral concentration & 82 & All chromosomes & $1.0-23.0$ & Peleg et al. (2009) \\
\hline & Trait related to protein and starch in grain & 35 & $\begin{array}{l}1 \mathrm{D}, 2 \mathrm{~A}, 2 \mathrm{D}, 3 \mathrm{~B}, 3 \mathrm{D}, 5 \mathrm{~A}, 6 \mathrm{~A}, 6 \mathrm{~B} \\
6 \mathrm{D} \text { and } 7 \mathrm{~B}\end{array}$ & $7.99-40.52$ & Sun et al. (2008) \\
\hline & Grain protein content & 13 & $2 \mathrm{~A}, 2 \mathrm{~B}, 2 \mathrm{D}, 3 \mathrm{D}, 4 \mathrm{~A}, 6 \mathrm{~B}, 7 \mathrm{~A}$ and $7 \mathrm{D}$ & $2.95-32.44$ & Prasad et al. (2003) \\
\hline & Grain protein content & 7 & $4 \mathrm{~B}, 5 \mathrm{~A}, 6 \mathrm{~A}, 6 \mathrm{~B}, 7 \mathrm{~A}$ and $7 \mathrm{~B}$ & $17.0-31.7$ & Blanco et al. (2002) \\
\hline
\end{tabular}


Table 1 (continued)

\begin{tabular}{|c|c|c|c|c|c|}
\hline Crop & Trait & $\begin{array}{l}\text { No. of QTLs } \\
\text { identified }\end{array}$ & Linkage group & $\begin{array}{l}\text { Phenotypic varia- } \\
\text { tion explained (\%) }\end{array}$ & References \\
\hline \multirow[t]{9}{*}{ Maize } & Starch content & 8 & $1,2,3,7$, and 9 & $5.45-6.84$ & Lin et al. (2019) \\
\hline & Starch granule size & 7 & 3,6 and 7 & - & Liu et al. (2018) \\
\hline & Kernel oil and protein content & 21 & All except 9 & $4.6-11.4$ & Yang et al. (2016) \\
\hline & $\begin{array}{l}\text { Mineral content, concentration and grain } \\
\text { yield }\end{array}$ & 74 & All chromosomes & $5.84-38.14$ & Gu et al. (2015) \\
\hline & Grain protein content & 16 & $3,5,6,7,8$ and 9 & $4.4-13.4$ & Yang et al. $(2014 a, b)$ \\
\hline & Oil, protein and starch content in grain & 22 & All chromosomes & $2.4-20.6$ & Guo et al. (2013) \\
\hline & Grain starch and grain-oil content & 37 & $1,3,4,5,8,9$ and 10 & $3.24-12.35$ & Yang et al. (2013) \\
\hline & Grain protein concentration & 5 & $3,6,8$ and 10 & $6.2-13.4$ & Li et al. (2009) \\
\hline & Fatty acid composition in kernel oil & 18 & All except 4 and 5 & $15.4-59.6$ & Wassom et al. (2008) \\
\hline
\end{tabular}

variety release. In such cases, strengthening the breeding strategies and modernizing the approaches are required to meet the challenges faced by agriculture, on time.

\section{Marker-assisted backcrossing and recurrent selection}

Marker-assisted backcrossing (MABC) is the introgression of a genomic region (QTL or locus or gene) contributing the desired trait from a donor genotype into a breeding line or elite cultivar without linkage drag through backcrossing after multiple generations. The resultant product of MABC contains the whole genome of an elite parent with the genetic loci or QTL or gene(s) contributing to the desired phenotype from the donor parent (Gupta et al. 2010). Quantity of molecular marker used, the strength of marker association with the phenotype, undesirable linkage drags, and size of the population used for each generation of backcrossing determines the efficiency of MABC. This method has been used extensively to generate superior lines of varieties for biotic and abiotic stress tolerance. For instance, NILs of drought-tolerant rice have been developed through introgression of root QTLs derived from a drought-tolerant japonica upland cultivar CT9993 into a lowland susceptible indica cultivar IR20 (Suji et al. 2012). Yang et al. (2019) had introgressed the blast resistance gene, $\mathrm{Pi}$, into an elite line by coupling MABC with genomics-based background selection. Kang et al. (2019) exploited the rapid generation advance system for expedited development of near-isogenic lines (NIL) from rice stripe virus resistant and susceptible parents, followed by MABC to develop a virus-resistant line in a short duration. In peanut, MABC assisted in developing elite lines with a high oleic/linoleic fatty acid ratio (Bera et al. 2019). In chickpea, Mannur et al. (2019) had developed Fusarium wilt resistant high yielding desi chickpea cultivars, Super Annigeri 1, and improved JG 74 lines in a record time of 10 years. Significant efforts have also been made to introgress, especially the genes and major QTLs regulating submergence, drought, and salinity tolerance as well as bacterial blight, sheath blight and blast resistance to develop stress-tolerant improved cultivars with enhanced yield and productivity in rice (Singh et al. 2019).

The marker-assisted recurrent selection (MARS) was introduced to counter the inefficiency of MABC in transferring multiple QTLs regulating complex traits like yield or broad-spectrum disease resistance. MARS involves the detection and selection of large QTLs or multiple genomic regions controlling complex agronomic traits within a single or across the populations and their pyramiding in a single genotype (Ribaut et al. 2010; Kulwal et al. 2011). This approach makes use of the $\mathrm{F}_{2}$ population and is most effective for cross-pollinating species. In disparity with MABC, favourable alleles may be contributed by both the parents, and the selected improved genotype becomes the chimera of their parents. The superior allele enrichment involves the phenotypic and marker effect for desired traits in the $\mathrm{F}_{2}$ population, followed by two or multiple cycles of markerassisted selection (Eathington et al. 2007). In the past few years, the Hyderabad situated International Maize and Wheat Improvement Center (CIMMYT) has made significant headway in the development of drought-tolerant maize inbred lines through MARS approach in their Asia Maize Drought Tolerance (AMDROUT) project. Other applications of this method have also been reported from rice, wheat, barley, soybean, cotton, pea, and sunflower improvement, particularly for evolving durable resistance.

\section{Genomic selection and speed breeding}

Genomic selection (GS) or genome-wide selection (GWS) utilizes the large-scale DNA markers dispersed throughout the genome to develop superior germplasm lines. Thus, the 
Fig. 2 Mapping of quantitative trait loci associated with complex agronomic traits and their application in genomics-assisted breeding. Linkage analysis in mapping population segregating for desired phenotype conquer QTL identification which generally employs in MAS

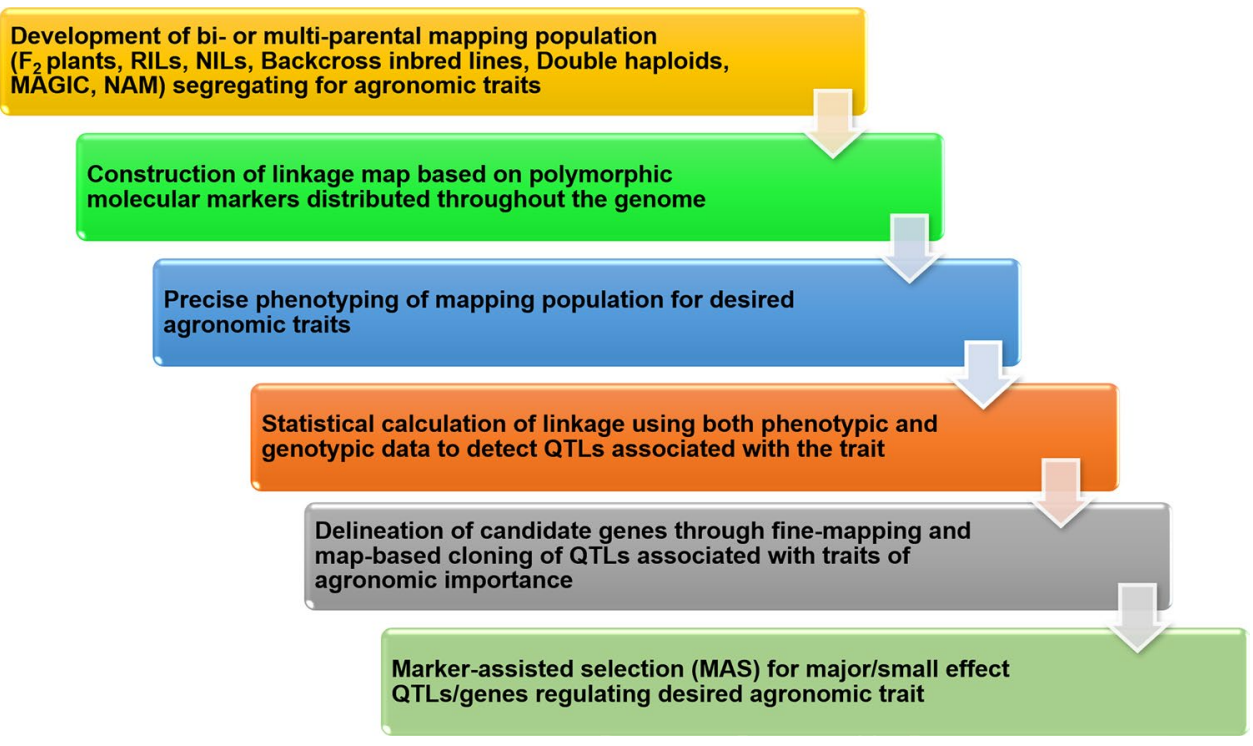

genomic selection approach has the potential to capture multiple QTLs/genes widely distributed with minor additive effects. Vigorous phenotyping is not mandatory for a breeding population, and subsequent offspring selection primarily focused on genotypic predictions, which combines the genomic and pedigree data for several generations of the breeding cycle (Nakaya and Isobe 2012). Genomic estimated breeding value (GEBV), the sum of the information index with a combined effect of genome-wide molecular markers, is the basis of recurrent selection (Singh et al. 2017). Highdensity molecular markers where each QTLs are in linkage disequilibrium with a minimum of single genomic markers are prerequisites for precise GEBV, and thus, for GWS (Habier et al. 2007). The success of GS also depends on the quantity and diversity of the training population (breeding lines selected for the GWS programme). The reduced number of selection events has decreased the time and cost of breeding. This approach can be equally applicable for both cross- and self-pollinated species with slight alterations (Bernardo 2010). Few examples of crop improvement through this approach are the development of wheat lines resistant to stem rust caused by Puccinia graminis f. sp. tritici (Rutkoski et al. 2010), drought-tolerant high-yielding lines in maize (Ziyomo and Bernardo 2013), improved yield and related traits under drought in chickpea (Li et al. 2018), and improved productivity in superior hybrids of rice (Cui et al. 2020). GS has also expanded its horizon towards underutilized or less studied crops for their improvement. de C. Lara et al. (2019) have demonstrated the use of GS in an autotetraploid forage grass, Panicum maximum. Similarly, in miscanthus, Slavov et al. (2019) have combined index selection and genomic prediction to achieve multiple breeding targets. These include increased biomass, delayed flowering, reduced lignin, and increased cellulose contents. In cassava,
Torres et al. (2019) have deployed GS for early selection and breeding for agronomic traits such as fresh root yield, dry matter content, dry yield, fresh shoot yield, and harvest index. These reports suggest the popularity and applicability of GS in enhancing the traits at a quicker phase that might lead to the early release of improved genotypes for agricultural production.

In case of breeding, time is an important factor that decides the release of genotypes to the farmers. Conventional breeding takes 3-7 years for crossing experiments, followed by 4-5 years for testing the yield, diseases and quality, and another 1-3 years for the release of varieties. Altogether, considerable time is invested in improving a single genotype or variety. Given this, the approach of modulating day-light and duration for accelerating the life cycle, termed 'speed breeding', has been introduced (Fig. 3). This recently developed speed breeding technology shortens the breeding cycle by accelerating crop generation by providing controlled rapid growth-promoting conditions in glasshouses and growth chambers (Watson et al. 2018; Ghosh et al. 2018). By modulating lighting, photoperiod, humidity, temperature, and other factors, the approach can achieve six generations per year for crops like wheat, barley, chickpea, and canola (Hickey et al. 2019). In contrast, in the glasshouse, these crops can undergo only three generations a year (Hickey et al. 2019). Early anthesis was reported from plants grown under speed breeding setup with fully viable mature seeds. Seed produced (g per plant) was unaffected between speed breeding and normal photoperiod conditions in almost all crops (Watson et al. 2018). The adaptation of technique in the breeding programme will accelerate the generation of mapping populations, reduce the duration of $\mathrm{MABC} /$ MARS/GWS, and expedite the progression towards homozygosity. Apart from major crops that are mostly annual or 
biannual, the method also has immense potential to hasten the improvement of woody shrub or perennial plants. The optimization of methods which headed towards the reduction of juvenile phase from 5 years to 10 months in apple and 7 to 2 years in chestnut are some example of the application of accelerated breeding cycle in perennial crops (Baier et al. 2012; van Nocker and Gardiner 2014). Rana et al. (2019) had coupled marker-assisted selection with speed breeding for developing salt-tolerant rice lines. Similarly, Bauerle (2019) has shown that the generation per year of hops could be enhanced from one (under field conditions) to four (through speed breeding) that could accelerate selection for flower yield and quality in this crop. Jighly et al. (2019) have combined GS with speed breeding to enhance genetic gains in allogamous plants like tall fescue. The approach named SpeedGS is gaining popularity among the breeders for achieving higher genetic gain per cycle, especially for traits with low heritability.

\section{Biotechnological interventions for crop improvement}

Transgenic or genetically modified (GM) crops have modified genomes at gene level achieved through several genetic engineering techniques. While breeding is time-consuming and allows only the transfer of genetic information from closely related species, genetic engineering or transgenebased research facilitates the transfer of genes from any source into the plants. However, an established protocol for introducing the gene into host species and rigorous selection is required to achieve greater success. Agrobacterium tumefaciens-mediated genetic transformation is one of the reliable approaches being used to achieve stable transgenic lines. In contrast, other techniques, including particle bombardment (biolistics), sonication, and electroporation, are used for transient expression of the foreign DNA. Singh and Prasad (2016) had comprehensively discussed the merits and demerits of $A$. tumefaciens-mediated genetic transformation in cereals. The prime bottleneck in this approach is the lack of optimized protocol for several important species, and the optimization is a time consuming and labour-intensive

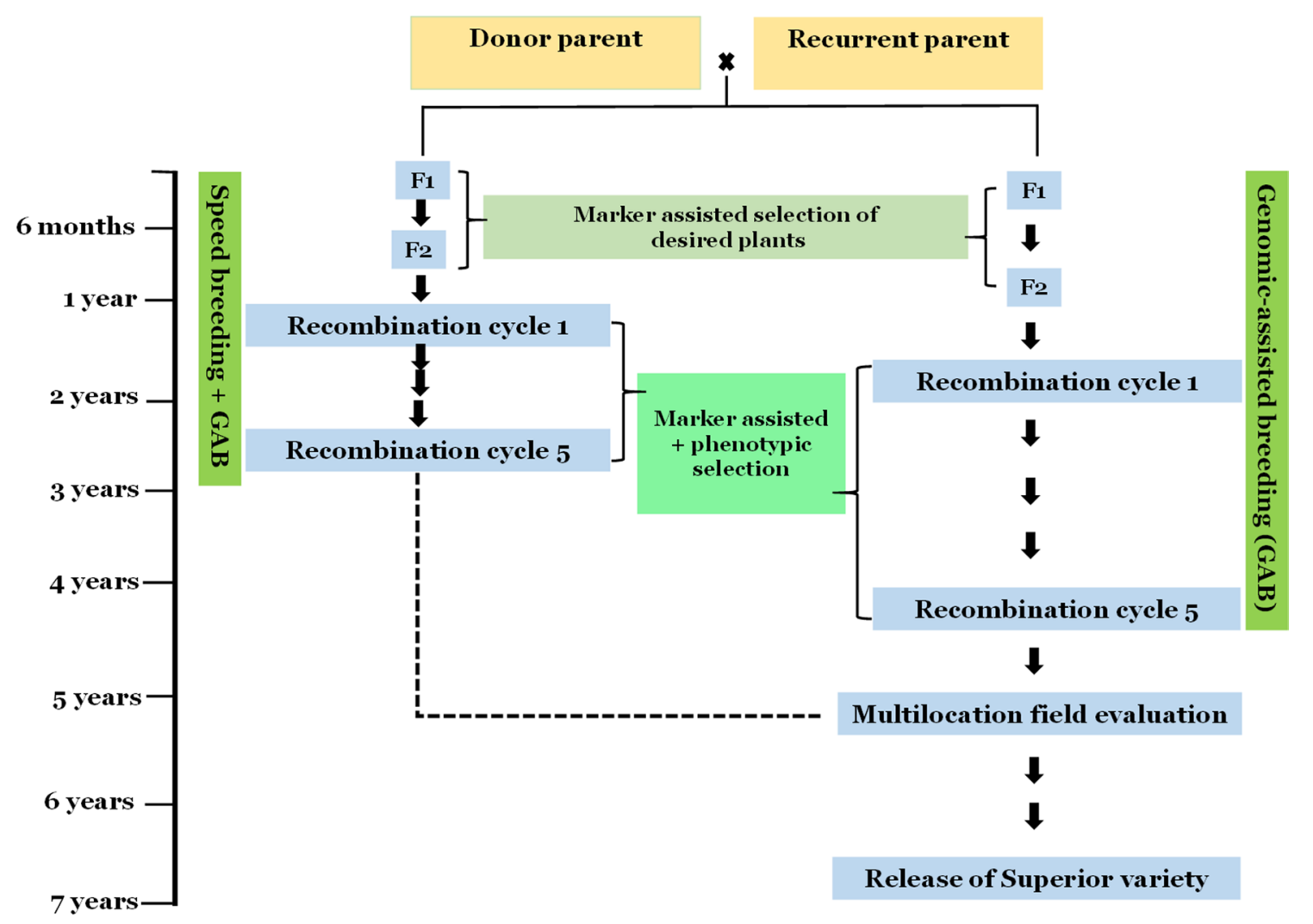

Fig. 3 Diagrammatic representation of the application of speed breeding in genomic-assisted breeding. Speed breeding significantly reduces the length of breeding cycle and accelerates the process of crop improvement. Conventional marker-assisted breeding (MAB) approximately takes 7-8 years to release an improved cereal variety while speed-breeding-assisted $\mathrm{MAB}$ would be completed within 3-4 years 
process. Achieving higher transformation efficiency is another issue that requires the fine-tuning of the experimental parameters. Once established, the protocol will serve as a key to introduce several genes into the target genome to attain better performance and phenotype. So far, 525 transgenics in 32 crops have been commercialized, of which Zea mays accounts for the highest number. Cultivation of transgenic crops has boosted agricultural productivity to about $22 \%$ leading to a $68 \%$ increase in profits (Kumar et al. 2020). Several genetic engineering technologies have been utilized for crop improvement, which is briefly discussed in the following sections (Fig. 4). Bt cotton has contributed to the Indian economy for a while, and in low-income countries like Bangladesh, Bt brinjal has secured its economy and livelihood of farmers. Despite these advantages, the public acceptance of transgenic crops has been quite low, and concerns have been raised regarding ecological hazards and safety-related issues in the context of human consumption. However, there is no scientific evidence that shows transgenic crops to cause health hazards (Tsatsakis et al. 2017; de Vos and Swanenburg 2018). Irrespective of these, biotechnology holds the key to the future of agriculture as the challenges faced by the farming sector are on a steady rise. At present, intensive agriculture is securing the life and livelihood of farmers and contributes to the global stock of grains and vegetables; however, issues like the spread of new diseases, insect/pest attack, erroneous rainfall, lack of soil fertility due to overuse of synthetic fertilizers, monotonous cropping, etc. could soon pose a serious threat to the ongoing agriculture. Plants need to withstand multiple stresses rather than single stress in their environment. Modulation of genes that regulate multiple stress responses through biotechnological interventions will help in the development of plants with enhanced efficiency under such conditions (Pandey et al. 2020). Several crops have been modified using biotechnology and have either been released or have the potential to be released. Examples of such crop species have been provided in Table 2. While addressing climate change and introducing good farming practices receives importance on one hand, it is also imperative to release varieties that could be climate-resilient or sustain in abnormal conditions, thus securing the food security of global population.

\section{Expression and overexpression of candidate genes for desired phenotype}

Gene cloning and isolation have facilitated the pulling out of a target gene from any genome that can then be transformed into any other genome for its expression. Expression of 'Cry' gene of Bacillus thuringiensis in plants is a typical example of this approach, and it is still popular since there is a rise in pests and insects that attacks plants. Expression of genes from other plant species for enhancing the agronomic or stress tolerance traits of target crops is also being practiced for a while. DREB (dehydration responsive element binding) protein-encoding genes are one such class of genes that were frequently isolated from one species and expressed in another for enhancing the tolerance to different abiotic and biotic stresses. Further, these expression and overexpression strategies also assist in elucidating the function of genes, which is an important task considering a large number of genes are at our disposal due to the advancement of NGS technologies. Their functional characterization becomes essential not only for basic research but also for application purposes. The T-DNA insertion lines of Arabidopsis thaliana have served as a vital resource for elucidating gene function. The next step after functional characterization is to utilize the gene for crop improvement programmes, and one of the most widely used methods is the overexpression of candidate genes. Several success stories depict the immense potential of gene overexpression in crops. Overexpression of ARGOS genes in Zea mays leads to a reduction in sensitivity to ethylene, and transgenic plants show enhanced drought resistance as well as higher grain yield in well-watered as well as drought conditions (Shi et al. 2015). Similarly, transgenic Glycine max plants overexpressing GmWRIlb show higher oil content and improved plant architecture under field conditions (Guo et al. 2020). The list for crop improvement for biotic and abiotic stresses, nutritional enhancement, increase in yield, biofuel production, herbicide resistance, etc., through overexpression approach is quite long with new additions at an ever-increasing rate. Some recent examples have been presented in Supplementary Table 1 . The functional validation of new candidates is also increasing at a rapid pace generating novel resources for crop improvement programmes (Lata and Prasad 2011; Puranik et al. 2012; Singh et al. 2020). The availability of genome sequence information in public domains had facilitated the large-scale analysis of genes and gene families, and characterizing those genes for their physiochemical properties, genomic composition, promoter elements, and expression profiling in response to stress, hormonal treatments and developmental stages had pinpointed several candidate genes that could be subjected to overexpression in target organisms for enhancing the trait-of-interests.

\section{RNA interference for in vivo knockdown of target genes}

The discovery of RNAi was a breakthrough in the history of biology, and since its finding, it has been widely utilized in functional genomics, reverse genetics and crop improvement (Rosa et al. 2018). RNAi pathway involves the generation of small RNAs (sRNA), which include short interfering RNA (siRNA), microRNA (miRNA), transacting siRNA (ta-siRNA) and natural-antisense siRNA 


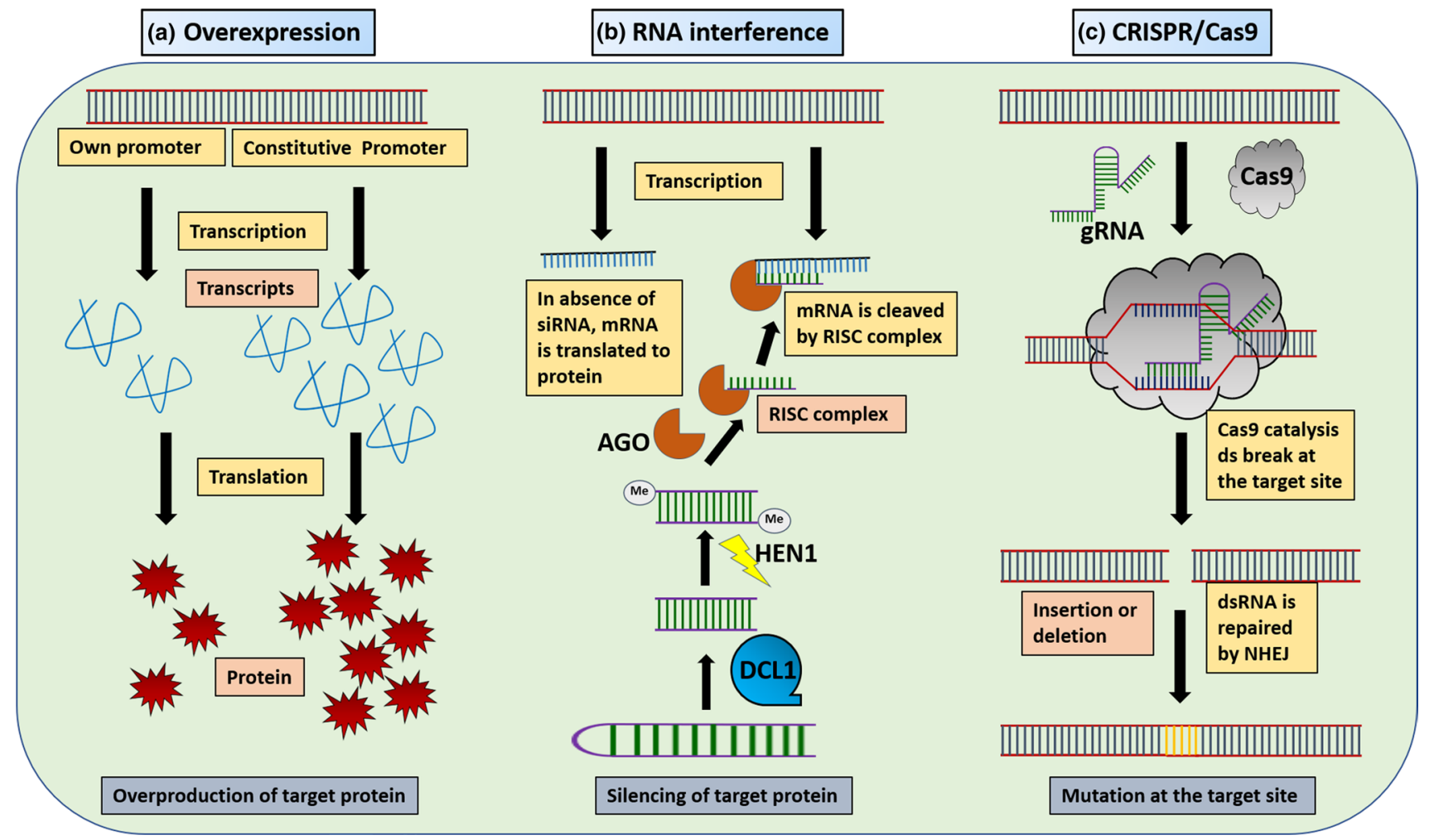

Fig. 4 Strategies for crop improvement through biotechnological approaches. a Overexpression leads to greater transcription of target gene which can be translated into protein; b RNA interference leads to downregulation of target gene; $\mathbf{c}$ Gene editing through CRISPR/ Cas9 leads to insertions or deletions at target site which gives rise to mutations

Table 2 Genetically engineered crops either released (*) or having the potential to be released (+)

\begin{tabular}{|c|c|c|c|c|}
\hline Crop species & Gene & Technology & Trait improved & References \\
\hline Rice* & $\begin{array}{l}\text { Phytoene synthase, phytoene desaturase, } \\
\text { lycopene- } \beta \text {-cyclase }\end{array}$ & Overexpression & Golden rice-provitamin A-rich rice & Ye et al. (2000) \\
\hline Rice $^{+}$ & $\begin{array}{l}\text { Phytoene synthase, phytoene desaturase, } \\
\beta \text {-carotene ketolase, and } \beta \text {-carotene } \\
\text { hydroxylase }\end{array}$ & Overexpression & $\begin{array}{l}\text { aSTARice-astaxanthin-rich biofortified } \\
\text { rice }\end{array}$ & Zhu et al. (2018) \\
\hline Tomato $^{+}$ & $\begin{array}{l}\text { Self-pruning, ovate, fasciated, fruit } \\
\text { weight } 2.2 \text {, multiflora and lycopene- } \beta \text { - } \\
\text { cyclase }\end{array}$ & Gene editing & $\begin{array}{l}\text { Improved size, number and lycopene } \\
\text { content of fruit }\end{array}$ & Zsögön et al. (2018) \\
\hline Cotton* & Crystalline endotoxin & Overexpression & Insect-resistant cotton & Umbeck (1992) \\
\hline Tomato* & Polygalacturonase & RNAi & $\begin{array}{l}\text { Flavr Savr tomato reduction in polyga- } \\
\text { lacturonase activity leading to delayed } \\
\text { fruit ripening }\end{array}$ & Sheehy et al. (1988) \\
\hline Canola* & Tryptophan decarboxylase & Overexpression & Low indole glucosinolate canola & Chavadej et al. (1994) \\
\hline Potato $^{+}$ & Amaranth albumin 1 & Overexpression & High-protein-content potato & Chakraborty et al. (2010) \\
\hline Maize $^{+}$ & Waxy & Gene editing & High-amylopectin-content corn & Waltz (2016) \\
\hline
\end{tabular}

(NAT-siRNA) which mediate silencing or epigenetic regulation of their target genes (Prasad et al. 2019). RNAi can be utilized by both transformative and non-transformative strategies. Transformative RNAi has been used in several modified forms like artificial miRNA (amiRNA), artificial ta-siRNA (ata-siRNA), hairpin RNA (hpRNA), intrinsic direct repeat, 3 '-untranslated region (UTR) direct repeat, terminator-less, single-stranded promoter antisense and intron delivered promoter hpRNA (Guo et al. 2016). Numerous examples can be cited where RNAi has been 


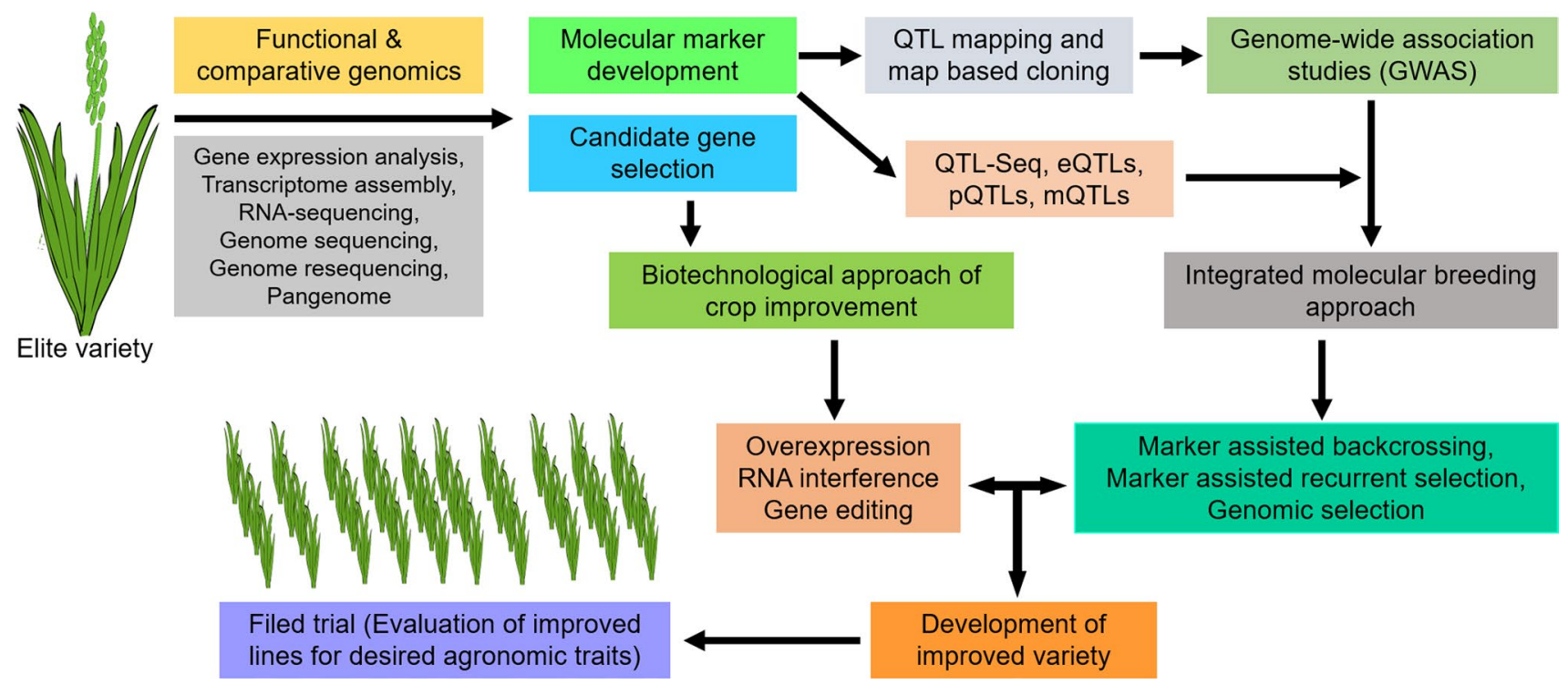

Fig. 5 Application of functional and comparative genomics in marker-assisted breeding and biotechnological approaches for crop improvement. The candidate gene(s) identified from functional genomic studies can be introduced through genetic engineering or tar-

successfully utilized for improving important traits like modification of plant architecture, improvement in fruit quality in terms of high $\beta$-carotene and lycopene content, enhanced shelf life, nutritional enhancement like low gluten content, reduction in toxic terpenoids, biotic stress resistance against viruses, fungi, bacteria and nematodes; and abiotic stress resistance to heat, drought, salinity, and cold (Kamthan et al. 2015).

The non-transformative RNAi technique, spray induced gene silencing (SIGS), has gained widespread attention due to its low cost of application and feasibility of use. It involves spraying plants with double-stranded (ds) RNA/siRNA and has been successfully utilized for controlling insect pests, which are the carriers of several viral pathogens (Cagliari et al. 2019; Worrall et al. 2019). Plants sprayed with dsRNA/ sRNA targeting DCL1 and DCL2 of Botrytis cinerea showed a significant reduction in grey mold disease symptoms highlighting the potential of this technology for the generation of next-generation eco-friendly biofungicides (Wang et al. 2016). Transgenic plants are met with criticism in several countries, and widespread acceptance is still lacking. It is estimated that about 130 million dollars are spent to bring a transgenic crop into commercialization (Rosa et al. 2018). However, despite all the efforts and promising features that GMOs have to offer, anti-GMO responses follow. Considering this, SIGS being a non-GMO approach has enormous potential for crop improvement, and it is also crucial that we devise new dsRNA/sRNA delivery strategies for silencing host as well as pathogen genes. Recent crop improvements utilizing RNAi as a tool have been summarized in geted modify through genome editing technology in crop species for improved agronomic traits. The other approach is through molecular breeding which employ molecular markers to identify genomic region associated with desired traits during breeding programme

Supplementary Table 2. In the functional genomics perspective, RNAi was useful in gene characterization studies; however, the recent advent of virus-induced gene silencing has now established its prominence over RNAi.

\section{Gene and genome editing}

Precise genome editing has revolutionized genetic engineering, and this started in 1996 when for the first time, it was shown that DNA binding zinc finger domains along with Fok1 endonuclease domains could cleave DNA at defined regions and act as site-specific nucleases (SSNs) (Kim et al. 1996). Further research led to the development of transcription activator-like effector nucleases (TALENs) and clustered regularly interspaced short palindrome repeats (CRISPR)/CRISPR-associated protein 9 (Cas9). Meganucleases (MegaN) recognize long DNA sequences that are greater than 14 nucleotides (nt) up to $40 \mathrm{nt}$. Since they have endonuclease activity, they produce double-stranded (ds) breaks at the recognition sites. However, their use in genome editing has been minimal because the variety of MegaNs available is very less and cannot be used for every locus (Silva et al. 2011). However, CRISPR/Cas9 has been more popular because of its ease of use compared to other genome editing technologies (Das et al. 2019). As the name suggests, CRISPR/Cas9 consists of two components: a single-guide 
RNA that is customizable and Cas9 endonuclease. Another prime requirement of the system is a Protospacer adjacent motif (PAM) (5'NGG3'), which is required for inducing ds breaks at the targeted sites in the genome. The breaks are repaired through either homology directed repair (HoDR) or non-homologous end joining (NHEJ). Since NHEJ is errorprone, repair leads to insertions or deletions at the target site (Khatodia et al. 2016).

CRISPR/Cas9 has shown immense potential for crop improvement, and several traits ranging from nutritional, biotic, and abiotic stress resistance have been enhanced (Jaganathan et al. 2018; Das et al. 2019) (Supplementary Table 3). However, there are certain limitations like the restrictions due to the requirement of PAM, off-target effects, and low efficacy of HoDR. Another problem is plant viruses that are known to mutate at tremendous rates (Prasad et al. 2020). Reports suggest that the evolution of editingresistant viruses may lead to viral escapes within a short span of time (Mehta et al. 2019). However, the technology is continually being supplemented with novel innovations overcoming some of the drawbacks.

Single nucleotide polymorphisms (SNPs) are responsible for certain elite traits in crops through genome-wide association studies (GWAS) (Zhao et al. 2019). Base editing is a new approach that can be utilized for editing these SNPs. Cas9 is fused with cytidine deaminase enzyme that has base conversion activity $(\mathrm{C} \rightarrow \mathrm{T}$ or $\mathrm{G} \rightarrow \mathrm{A})$, and this modified method does not require dsDNA as a repair template (Komor et al. 2016). The problem of low efficiency of HoDR is also overcome as it is not involved in the base conversion process. Conventional genome editing is associated with the insertion of DNA cassettes at random regions within the genome, and this may lead to other undesirable effects. The regulatory concerns for transgenics are another hindrance. To overcome these problems, DNA free genome editing was developed, which involves the delivery of preassembled CRISPR/Cas9 ribonucleoproteins (RNPs) to protoplasts by particle bombardment (Woo et al. 2015). The only problem with this method is that protoplast regeneration systems are not yet available for a majority of crops, but this can be overcome with a research focus in this direction. CRISPR/Cas9 is also limited due to the requirement of 5'NGG3' PAM, and Cas9 variants are essential to overcome this problem. CRISPR from Prevotella and Francisella 1 (Cpf1) endonuclease recognize T-rich PAMs, thus broadening the target range of the system (Zetsche et al. 2015). Several variants exploiting the CRISPR-based approach to achieve other functions had also been reported. For example, deactivating the nuclease domain and engineering a transcription enhancer to Cas9 could promote the expression of the target gene. Similar engineering of deaminase to the Cas9 protein facilitates the conversion of cytosine residues to thymine. Thus, CRISPR/ Cas9-based approach has multiple applications in editing the genes and genomes at base-pair level. Of note, the method is not considered as GM in several countries, which would encourage the use of CRISPR/Cas9 in developing lines that could meet the challenges currently faced by agriculture.

\section{Conclusions and future prospects}

The foremost challenge for crop scientists is to increase agricultural productivity to pursue the demand for food supply for a rapidly expanding global population, which is expected to reach approximately 10 billion by the mid of the twentyfirst century (United Nations, World Population Prospects 2017). On the one hand, global warming, constrained environmental conditions, and biotic factors are limiting crop yield. On the other hand, fertile farmland is also shrinking due to rapid urbanization and soil erosion. Besides, pandemic situations like the recent COVID-19 prevalence have introduced significant gaps in food and nutritional securities to the global population. Therefore, the rapid release of environmentally sustainable high yielding varieties is required. Molecular breeding and genetic manipulation have emerged as the two most potent technologies which have the potential to attain food and energy security for the coming years (Fig. 5). Advances in NGS technology have enabled the incorporation of genomics with various disciplines of crop breeding. Large-scale genomic markers and high-throughput genotyping are being applied in breeding have accelerated the quantity and cost of cultivar development. Similarly, functional and comparative genomics have provided the platform for gene discovery and their functional characterization. The key gene or genes regulating a molecular pathway are being genetically engineered or edited to develop phenotypically improved crop lines. Whatever be the approach, either molecular breeding or biotechnological tools, the ultimate intention is to ensure food for all through increased productivity per plant and minimize yield loss caused due to external factors. The collaborative research investments of various branches of science are paramount to sustainable crop improvement.

Author contribution statement MP conceived and outlined the review. RKS and AP prepared the first draft, tables, and figures; MM and SKP improved the manuscript and provided revisions to it. All authors have read and approved the final version of this manuscript.

Acknowledgements Authors' work in the area of plant molecular genetics and genomics is supported by the Core Grant of National Institute of Plant Genome Research, New Delhi, India. RKS and AP acknowledge the Council of Scientific and Industrial Research, Government of India, India, for the award of research fellowship. MM 
acknowledges the INSPIRE Faculty Award from the Department of Science and Technology, Government of India, India. The authors are thankful to DBT-eLibrary Consortium (DeLCON) for providing access to e-resources.

\section{Compliance with ethical standards}

Conflict of interest The authors declare that they have no conflict of interest.

\section{References}

Alexandrov N, Tai S, Wang W, Mansueto L, Palis K, Fuentes RR, Ulat VJ, Chebotarov D, Zhang G, Li Z, Mauleon R, Hamilton RS, McNally KL (2015) SNP-seek database of SNPs derived from 3000 rice genomes. Nucleic Acids Res 43:D1023-D1027

Aluko G, Martinez C, Tohme J, Castano C, Bergman C, Oard JH (2004) QTL mapping of grain quality traits from the interspecific cross Oryza sativa $\times$ O. glaberrima. Theor Appl Genet 109:630-639

Arabidopsis Genome Initiative (2000) Analysis of the genome sequence of the flowering plant Arabidopsis thaliana. Nature 408:796-815

Azodi CB, Pardo J, VanBuren R, de Los Campos G, Shiu SH (2020) Transcriptome-based prediction of complex traits in maize. Plant Cell 32:139-151

Baier KM, Maynard C, Powell W (2012) Early flowering in chestnut species induced under high dose light in growth chambers. J Am Chestnut Found 26:8-10

Bailey-Serres J, Parker JE, Ainsworth EA et al (2019) Genetic strategies for improving crop yields. Nature 575:109-118

Bajaj D, Srivastava R, Nath M, Tripathi S, Bharadwaj C, Upadhyaya HD, Tyagi AK, Parida SK (2016) EcoTILLING-based association mapping efficiently delineates functionally relevant natural allelic variants of candidate genes governing agronomic traits in chickpea. Front Plant Sci 7:450

Bauerle WL (2019) Disentangling photoperiod from hop vernalization and dormancy for global production and speed breeding. Sci Rep 9:16003

Bayer PE, Golicz AA, Tirnaz S, Chan CK, Edwards D, Batley J (2019) Variation in abundance of predicted resistance genes in the Brassica oleracea pangenome. Plant Biotechnol J 17:789-800

Bera SK, Kamdar JH, Kasundra SV et al (2019) Steady expression of high oleic acid in peanut bred by marker-assisted backcrossing for fatty acid desaturase mutant alleles and its effect on seed germination along with other seedling traits. PLoS One 14:e0226252

Bernardo R (2010) Genome wide selection with minimal crossing in self-pollinated crops. Crop Sci 50:624-627

Blanco A, Pasqualone A, Troccoli A, Di Fonzo N, Simeone R (2002) Detection of grain protein content QTLs across environments in tetraploid wheats. Plant Mol Biol 48:615-623

Cagliari D, Dias NP, Galdeano DM et al (2019) Management of pest insects and plant diseases by non-transformative RNAi. Front Plant Sci 10:1319

Calayugan MIC, Formantes AK, Amparado A, Descalsota-Empleo GI, Nha CT et al (2020) Genetic analysis of agronomic traits and grain iron and zinc concentrations in a doubled haploid population of rice (Oryza sativa L.). Sci Rep 10:2283

Chakraborty S, Chakraborty N, Agrawal L et al (2010) Next-generation protein-rich potato expressing the seed protein gene Am A1 is a result of proteome rebalancing in transgenic tuber. Proc Natl Acad Sci USA 107:17533-17538
Chavadej S, Brisson N, McNeil JN, De Luca V (1994) Redirection of tryptophan leads to production of low indole glucosinolate canola. Proc Natl Acad Sci USA 91:2166-2170

Crossa J, Pérez-Rodríguez P, Cuevas J et al (2017) Genomic selection in plant breeding: methods, models, and perspectives. Trends Plant Sci 22:961-975

Cui Y, Li R, Li G, Zhang F, Zhu T, Zhang Q, Ali J, Li Z, Xu S (2020) Hybrid breeding of rice via genomic selection. Plant Biotechnol J 18:57-67

Das A, Sharma N, Prasad M (2019) CRISPR/Cas9: a novel weapon in the arsenal to combat plant diseases. Front Plant Sci 9:1-8

de C. Lara LA, Santos MF, Jank L et al (2019) Genomic selection with allele dosage in Panicum maximum Jacq. G3 (Bethesda) 9:2463-2475

de Vos CJ, Swanenburg M (2018) Health effects of feeding genetically modified (GM) crops to livestock animals: a review. Food Chem Toxicol 117:3-12

Eathington SR, Crosbie TM, Edwards MD, Reiter RS, Bull JK (2007) Molecular markers in a commercial breeding program. Crop Sci 47:S154-S163

Fatiukha A, Filler N, Lupo I, Lidzbarsky G, Klymiuk V, Korol AB, Pozniak C, Fahima T, Krugman T (2020) Grain protein content and thousand kernel weight QTLs identified in a durum $\times$ wild emmer wheat mapping population tested in five environments. Theor Appl Genet 133:119-131

Feng N, He Z, Zhang Y, Xia X, Zhang Y (2013) QTL mapping of starch granule size in common wheat using recombinant inbred lines derived from a PH82-2/Neixiang 188 cross. Crop J 1:166-171

Feng Y, Lu Q, Zhai R, Zhang M, Xu Q, Yang Y, Wang S, Yuan X, Yu $\mathrm{H}$, Wang Y, Wei X (2016) Genome wide association mapping for grain shape traits in indica rice. Planta 244:819-830

Fracasso A, Trindade LM, Amaducci S (2016) Drought stress tolerance strategies revealed by RNA-Seq in two sorghum genotypes with contrasting WUE. BMC Plant Biol 16:115

Fu X, Qi Z, Li S (2011) QTL detection for water-soluble oligosaccharide content of grain in common wheat. Mol Plant Breed 2:68-74

Garcia-Oliveira AL, Tan L, Fu Y, Sun C (2009) Genetic identification of quantitative trait loci for contents of mineral nutrients in rice grain. J Integr Plant Biol 51:84-92

Garrido-Cardenas JA, Mesa-Valle C, Manzano-Agugliaro F (2018) Trends in plant research using molecular markers. Planta 247:543-557

Ghosh S, Watson A, Gonzalez-Navarro OE, Ramirez-Gonzalez RH et al (2018) Speed breeding in growth chambers and glasshouses for crop breeding and model plant research. Nat Protoc 13:2944-2963

Giancaspro A, Giove SL, Zacheo SA, Blanco A, Gadaleta A (2019) Genetic variation for protein content and yield-related traits in a durum population derived from an inter-specific cross between hexaploid and tetraploid wheat cultivars. Front Plant Sci 10:1509

Goff SA, Ricke D, Lan TH, Presting G et al (2002) A draft sequence of the rice genome (Oryza sativa L. ssp. japonica). Science 296:92-100

Golicz AA, Batley J, Edwards D (2016a) Towards plant pangenomics. Plant Biotechnol J 14:1099-1105

Golicz AA, Bayer PE, Barker GC, Edger PP et al (2016b) The pangenome of an agronomically important crop plant Brassica oleracea. Nat Commun 7:13390

Gu R, Chen F, Liu B, Wang X, Liu J, Li P, Pan Q, Pace J, Soomro AA, Lübberstedt T, Mi G, Yuan L (2015) Comprehensive phenotypic analysis and quantitative trait locus identification for grain mineral concentration, content, and yield in maize (Zea mays L.). Theor Appl Genet 128:1777-1789

Guo Y, Yang X, Chander S, Yan J, Zhang J, Song T, Li J (2013) Identification of unconditional and conditional QTL for oil, protein and starch content in maize. Crop J 1:34-42 
Guo Q, Liu Q, Smith NA et al (2016) RNA silencing in plants: mechanisms, technologies and applications in horticultural crops. Curr Genom 17:476-489

Guo W, Li G, Wang N et al (2020) $\mathrm{A} \mathrm{Na}^{+} / \mathrm{H}^{+}$antiporter, K2-NhaD, improves salt and drought tolerance in cotton (Gossypium hirsutum L.). Plant Mol Biol 102:553-567

Gupta PK, Kumar J, Mir RR, Kumar A (2010) Marker assisted selection as a component of conventional plant breeding. Plant Breed Rev 33:145-217

Habash DZ, Kehel Z, Nachit M (2009) Genomic approaches for designing durum wheat ready for climate change with a focus on drought. J Exp Bot 60:2805-2815

Habier D, Fernando RL, Dekkers JC (2007) The impact of genetic relationship information on genome-assisted breeding values. Genetics 177:2389-2397

Han B, Wang C, Tang Z, Ren Y, Li Y, Zhang D, Dong Y, Zhao X (2015) Genome-wide analysis of microsatellite markers based on sequenced database in Chinese spring wheat (Triticum aestivum L.). PLoS One 10:e0141540

He Y, Han Y, Jiang L, Xu C, Lu J, Xu M (2006) Functional analysis of starch-synthesis genes in determining rice eating and cooking qualities. Mol Breed 18:277-290

Hickey LT, Hafeez AN, Robinson H et al (2019) Breeding crops to feed 10 billion. Nat Biotechnol 37:744-754

Hirsch CN, Foerster JM, Johnson JM, Sekhon RS et al (2014) Insights into the maize pan-genome and pan-transcriptome. Plant Cell 26:121-135

Hu ZL, Li P, Zhou MQ, Zhang ZH, Wang LX, Zhu LH, Zhu YG (2004) Mapping of quantitative trait loci (QTLs) for rice protein and fat content using doubled haploid lines. Euphytica 135:47-54

Hu Z, Zhang D, Zhang G, Kan G, Hong D, Yu D (2014) Association mapping of yield-related traits and SSR markers in wild soybean (Glycine soja Sieb. and Zucc.). Breed Sci 63:441-449

Hurgobin B, Edwards D (2017) SNP discovery using a pangenome: has the single reference approach become obsolete? Biology (Basel) 6:21

International Wheat Genome Sequencing Consortium (IWGSC), IWGSC RefSeq Principal Investigators, Appels R et al (2018) Shifting the limits in wheat research and breeding using a fully annotated reference genome. Science 361:eaar7191

International Rice Genome Sequencing Project (2005) The map-based sequence of the rice genome. Nature 436:793-800

Jaganathan D, Ramasamy K, Sellamuthu G et al (2018) CRISPR for crop improvement: an update review. Front Plant Sci 9:00985

Jaiswal V, Bandyopadhyay T, Gahlaut V, Gupta S et al (2019a) Genome-wide association study (GWAS) delineates genomic loci for ten nutritional elements in foxtail millet (Setaria italica L.). J Cereal Sci 85:48-55

Jaiswal V, Gupta S, Gahlaut V, Muthamilarasan M, Bandyopadhyay T, Ramchiary N, Prasad M (2019b) Genome-wide association study of major agronomic traits in foxtail millet (Setaria italica L.) using ddRAD sequencing. Sci Rep 9:5020

Jighly A, Lin Z, Pembleton LW et al (2019) Boosting genetic gain in allogamous crops via speed breeding and genomic selection. Front Plant Sci 10:1364

Kamthan A, Chaudhuri A, Kamthan M, Datta A (2015) Small RNAs in plants: recent development and application for crop improvement. Front Plant Sci 6:00208

Kang JW, Shin D, Cho JH et al (2019) Accelerated development of rice stripe virus-resistant, near-isogenic rice lines through markerassisted backcrossing. PLoS One 14:e0225974

Khatodia S, Bhatotia K, Passricha N et al (2016) The CRISPR/Cas genome-editing tool: application in improvement of crops. Front Plant Sci 7:00506
Kim YG, Cha J, Chandrasegaran S (1996) Hybrid restriction enzymes: zinc finger fusions to Fok I cleavage domain. Proc Natl Acad Sci USA 93:1156-1160

Kim NH, Sohn JK, Kim KM (2013) Physicochemical characteristics and QTL mapping associated with the lipid content of high-lipid rice. Am J Plant Sci 4:1949-1953

Kinoshita N, Kato M, Koyasaki K, Kawashima T, Nishimura T, Hirayama Y, Takamure I, Sato T, Kato K (2017) Identification of quantitative trait loci for rice grain quality and yield-related traits in two closely related Oryza sativa L. subsp. japonica cultivars grown near the northernmost limit for rice paddy cultivation. Breed Sci 67:191-206

Komor AC, Kim YB, Packer MS et al (2016) Programmable editing of a target base in genomic DNA without double-stranded DNA cleavage. Nature 533:420-424

Krishnappa G, Singh AM, Chaudhary S, Ahlawat AK, Singh SK, Shukla RB, Jaiswal JP, Singh GP, Solanki IS (2017) Molecular mapping of the grain iron and zinc concentration, protein content and thousand kernel weight in wheat (Triticum aestivum L.). PLoS One 12:e0174972

Kulwal PL, Thudi M, Varshney RK (2011) Genomics interventions in crop breeding for sustainable agriculture. In: Meyers RA (ed) Encyclopedia of sustainability science and technology. Springer, New York. https://doi. org/10.1007/978-1-4419-0851-3

Kumar K, Gambhir G, Dass A et al (2020) Genetically modified crops: current status and future prospects. Planta 251:91

Ladejobi O, Elderfield J, Gardner KA, Gaynor RC, Hickey J, Hibberd JM, Mackay IJ, Bentley AR (2016) Maximizing the potential of multi-parental crop populations. Appl Transl Genom 11:9-17

Lam HM, Xu X, Liu X, Chen W, Yang G et al (2010) Resequencing of 31 wild and cultivated soybean genomes identifies patterns of genetic diversity and selection. Nat Genet 42:1053-1059

Lata C, Prasad M (2011) Role of DREBs in regulation of abiotic stress responses in plants. J Exp Bot 62:4731-4748

Lee GH, Yun BW, Kim KM (2014) Analysis of QTLs associated with the rice quality related gene by double haploid populations. Int J Genom 2014:781832

Lesk C, Rowhani P, Ramankutty N (2016) Influence of extreme weather disasters on global crop production. Nature 529:84-87

Li Y, Wang Y, Wei M, Li X, Fu J (2009) QTL identification of grain protein concentration and its genetic correlation with starch concentration and grain weight using two populations in maize (Zea mays L.). J Genet 88:61-67

Li YH, Zhou G, Ma J, Jiang W et al (2014) De novo assembly of soybean wild relatives for pan-genome analysis of diversity and agronomic traits. Nat Biotechnol 32:1045-1052

Li Y, Ruperao P, Batley J, Edwards D, Khan T, Colmer TD, Pang J, Siddique KHM, Sutton T (2018) Investigating drought tolerance in chickpea using genome-wide association mapping and genomic selection based on whole-genome resequencing data. Front Plant Sci 9:190

Lin F, Zhou L, He B, Zhang X, Dai H, Qian Y, Ruan L, Zhao H (2019) QTL mapping for maize starch content and candidate gene prediction combined with co-expression network analysis. Theor Appl Genet 132:1931-1941

Liu X, Wan X, Ma X, Wan J (2011) Dissecting the genetic basis for the effect of rice chalkiness, amylose content, protein content, and rapid viscosity analyzer profile characteristics on the eating quality of cooked rice using the chromosome segment substitution line population across eight environments. Genome 54:64-80

Liu X, Wang Y, Wang SW (2012) QTL analysis of percentage of grains with chalkiness in Japonica rice (Oryza sativa). Genet Mol Res 11:717-724

Liu Z, Xin M, Qin J, Peng H, Ni Z, Yao Y, Sun Q (2015) Temporal transcriptome profiling reveals expression partitioning of 
homeologous genes contributing to heat and drought acclimation in wheat (Triticum aestivum L.). BMC Plant Biol 15:152

Liu N, Zhang Z, Xue Y, Meng S, Huang Y, Li W, Huang J, Tang J (2018) Identification of quantitative trait loci and candidate genes for maize starch granule size through association mapping. Sci Rep 8:14236

Liu C, Ding S, Zhang A, Hong K, Jiang H, Yang S, Ruan B, Zhang B, Dong G, Guo L, Zeng D, Qian Q, Gao Z (2020a) Development of nutritious rice with high zinc/selenium and low cadmium in grains through QTL pyramiding. J Integr Plant Biol 62:349-359

Liu Y, Du H, Li P et al (2020b) Pan-genome of wild and cultivated soybeans. Cell 182:162-176.e13

Lu K, Wei L, Li X, Wang Y, Wu J et al (2019) Whole-genome resequencing reveals Brassica napus origin and genetic loci involved in its improvement. Nat Commun 10:1154

Mannur DM, Babbar A, Thudi M, Sabbavarapu MM (2019) Super Annigeri 1 and improved JG 74: two Fusarium wilt-resistant introgression lines developed using marker-assisted backcrossing approach in chickpea (Cicer arietinum L.). Mol Breed 39:2

Marcotuli I, Gadaleta A, Mangini G, Signorile AM, Zacheo SA, Blanco A, Simeone R, Colasuonno P (2017) Development of a high-density SNP-based linkage map and detection of QTL for $\beta$-glucans, protein content, grain yield per spike and heading time in durum wheat. Int J Mol Sci 18:E1329

Mehta D, Stürchler A, Anjanappa RB, Zaidi SS, Hirsch-Hoffmann M, Gruissem W, Vanderschuren H (2019) Linking CRISPR-Cas9 interference in cassava to the evolution of editing-resistant geminiviruses. Genome Biol 20:80

Mir RR, Zaman-Allah M, Sreenivasulu N, Trethowan R, Varshney RK (2012) Integrated genomics, physiology and breeding approaches for improving drought tolerance in crops. Theor Appl Genet $125: 625-645$

Muthamilarasan M, Prasad M (2015) Advances in Setaria genomics for genetic improvement of cereals and bioenergy grasses. Theor Appl Genet 128:1-14

Muthamilarasan M, Prasad M (2017a) Exploiting genome sequence information to develop genomic resources for foxtail millet improvement. In: Prasad M (ed) The foxtail millet genome, pp $37-51$

Muthamilarasan M, Prasad M (2017b) Genetic determinants of drought stress tolerance in Setaria. In: Doust A, Diao X (eds) Genetics and genomics of Setaria, pp 267-289

Muthamilarasan M, Venkata Suresh B, Pandey G, Kumari K, Parida SK, Prasad M (2014) Development of 5123 intron-length polymorphic markers for large-scale genotyping applications in foxtail millet. DNA Res 21:41-52

Muthamilarasan M, Dhaka A, Yadav R, Prasad M (2016) Exploration of millet models for developing nutrient rich graminaceous crops. Plant Sci 242:89-97

Muthamilarasan M, Singh NK, Prasad M (2019) Multi-omics approaches for strategic improvement of stress tolerance in underutilized crop species: a climate change perspective. Adv Genet 103:1-38

Myles S, Peiffer J, Brown PJ, Ersoz ES, Zhang Z, Costich DE, Buckler ES (2009) Association mapping: critical considerations shift from genotyping to experimental design. Plant Cell 21:2194-2202

Nakaya A, Isobe SN (2012) Will genomic selection be a practical method for plant breeding? Ann Bot 110:1303-1316

Nica AC, Dermitzakis ET (2013) Expression quantitative trait loci: present and future. Philos Trans R Soc Lond B Biol Sci 368:20120362

Nigro D, Gadaleta A, Mangini G, Colasuonno P, Marcotuli I, Giancaspro A, Giove SL, Simeone R, Blanco A (2019) Candidate genes and genome-wide association study of grain protein content and protein deviation in durum wheat. Planta 249:1157-1175
Pandey G, Misra G, Kumari K, Gupta S, Parida SK, Chattopadhyay D, Prasad M (2013) Genome-wide development and use of microsatellite markers for large-scale genotyping applications in foxtail millet [Setaria italica (L.)]. DNA Res 20:197-207

Pandey S, Prasad A, Sharma N, Prasad M (2020) Linking the plant stress responses with RNA helicases. Plant Sci 299:110607

Park SG, Park HS, Baek MK, Jeong JM, Cho YC, Lee GM, Lee CM, Suh JP, Kim CS, Kim SM (2019) Improving the glossiness of cooked rice, an important component of visual rice grain quality. Rice (N Y) 12:87

Paterson AH, Bowers JE, Bruggmann R, Dubchak I et al (2009) The Sorghum bicolor genome and the diversification of grasses. Nature 457:551-556

Peleg Z, Cakmak I, Ozturk L, Yazici A, Jun Y, Budak H, Korol AB, Fahima T, Saranga Y (2009) Quantitative trait loci conferring grain mineral nutrient concentrations in durum wheat $\times$ wild emmer wheat RIL population. Theor Appl Genet 119:353-369

Pingali PL (2012) Green revolution: impacts, limits, and the path ahead. Proc Natl Acad Sci USA 109:12302-12308. https://doi. org/10.1073/pnas.0912953109

Prasad M, Kumar N, Kulwal PL, Röder MS, Balyan HS, Dhaliwal HS, Gupta PK (2003) QTL analysis for grain protein content using SSR markers and validation studies using NILs in bread wheat. Theor Appl Genet 106:659-667

Prasad A, Sharma N, Hari-Gowthem G, Muthamilarasan M, Prasad M (2020) Tomato yellow leaf curl virus: impact, challenges, and management. Trends Plant Sci 25:897-911

Prasad A, Sharma N, Muthamilarasan M et al (2019) Recent advances in small RNA mediated plant-virus interactions. Crit Rev Biotechnol 39:587-601

Puranik S, Sahu PP, Srivastava PS, Prasad M (2012) NAC proteins: regulation and role in stress tolerance. Trends Plant Sci 17:369-381

Qu C, Jia L, Fu F, Zhao H et al (2017) Genome-wide association mapping and Identification of candidate genes for fatty acid composition in Brassica napus L. using SNP markers. BMC Genom $18: 232$

Rana MM, Takamatsu T, Baslam M et al (2019) Salt tolerance improvement in rice through efficient snp marker-assisted selection coupled with speed-breeding. Int J Mol Sci 20:2585

Rao IS, Neeraja CN, Srikanth B, Subrahmanyam D (2018) Identification of rice landraces with promising yield and the associated genomic regions under low nitrogen. Sci Rep 8:9200

Ribaut JM, de Vicente MC, Delannay X (2010) Molecular breeding in developing countries: challenges and perspectives. Curr Opin Plant Biol 13:213-218

Rodziewicz P, Chmielewska K, Sawikowska A et al (2019) Identification of drought responsive proteins and related proteomic QTLs in barley. J Exp Bot 70:2823-2837

Roorkiwal M, Bharadwaj C, Barmukh R et al (2020) Integrating genomics for chickpea improvement: achievements and opportunities. Theor Appl Genet. https://doi.org/10.1007/s00122-02003584-2

Rosa C, Kuo Y-W, Wuriyanghan H, Falk BW (2018) RNA interference mechanisms and applications in plant pathology. Annu Rev Phytopathol 56:581-610

Roshanzamir H, Kordenaeej A, Bostani A (2013) Mapping QTLs related to $\mathrm{Zn}$ and $\mathrm{Fe}$ concentrations in bread wheat (Triticum aestivum) grain using microsatellite markers. Iran J Genet Plant Breed 2:1

Ruan Y, Yu B, Knox RE, Singh AK, DePauw R, Cuthbert R, Zhang W, Piche I, Gao P, Sharpe A, Fobert P (2020) High density mapping of quantitative trait loci conferring gluten strength in Canadian durum wheat. Front Plant Sci 11:170

Rutkoski JE, Heffner EL, Sorrells ME (2010) Genomic selection for durable stem rust resistance in wheat. Euphytica 179:161-173 
Safavi-Rizi V, Herde M, Stöhr C (2020) RNA-Seq reveals novel genes and pathways associated with hypoxia duration and tolerance in tomato root. Sci Rep 10:1692

Schatz MC, Maron LG, Stein JC, Hernandez Wences A et al (2014) Whole genome de novo assemblies of three divergent strains of rice, Oryza sativa, document novel gene space of aus and indica. Genome Biol 15:506

Schmutz J, Cannon SB, Schlueter J, Ma J et al (2010) Genome sequence of the palaeopolyploid soybean. Nature 463:178-183

Schnable PS, Ware D, Fulton RS, Stein JC et al (2009) The B73 maize genome: complexity, diversity, and dynamics. Science 326:1112-1115

Sheehy RE, Kramer M, Hiatt WR (1988) Reduction of polygalacturonase activity in tomato fruit by antisense RNA. Proc Nat Acad Sci USA 85:8805-8809

Shen Y, Zhang W, Liu X, Chen L, Liu S, Zheng L, Li J, Chen Y, Wu T, Yu Y, Zhong Z, Jiang L, Wan J (2012) Identification of two stably expressed QTLs for fat content in rice (Oryza sativa). Genome 55(8):585-590

Shi J, Habben JE, Archibald RL et al (2015) Overexpression of ARGOS genes modifies plant sensitivity to ethylene, leading to improved drought tolerance in both arabidopsis and maize. Plant Physiol 169:266-282

Shi T, Zhu A, Jia J et al (2020) Metabolomics analysis and metaboliteagronomic trait associations using kernels of wheat (Triticum aestivum) recombinant inbred lines. Plant J 103:279-292

Silva G, Poirot L, Galetto R et al (2011) Meganucleases and other tools for targeted genome engineering: perspectives and challenges for gene therapy. Curr Gene Ther 11:11-27

Singh RK, Prasad M (2016) Advances in Agrobacterium tumefaciensmediated genetic transformation of graminaceous crops. Protoplasma 253:691-707

Singh RK, Prasad M (2017) Genome wide association studies for improving agronomic traits in foxtail millet. In: Prasad M (ed) The Foxtail millet genome, pp 63-75

Singh RK, Sahu PP, Muthamilarasan M, Dhaka A, Prasad M (2017) Genomics-assisted breeding for improving stress tolerance of graminaceous crops to biotic and abiotic stresses: progress and prospects. In: Senthil-Kumar M (ed) Plant tolerance to individual and concurrent stresses, pp 59-81 https://doi. org/10.1007/978-81-322-3706-8_5

Singh RK, Shweta S, Muthamilarasan M, Rani R, Prasad M (2019) Study on aquaporins of Setaria italica suggests the involvement of SiPIP3;1 and SiSIP1;1 in abiotic stress response. Funct Integr Genom 19:587-596

Singh RK, Deshmukh R, Muthamilarasan M, Rani R, Prasad M (2020) Versatile roles of aquaporin in physiological processes and stress tolerance in plants. Plant Physiol Biochem 149:178-189

Slavov GT, Davey CL, Bosch M, Robson PRH, Donnison IS, Mackay IJ (2019) Genomic index selection provides a pragmatic framework for setting and refining multi-objective breeding targets in Miscanthus. Ann Bot 124:521-530

Sood P, Singh RK, Prasad M (2020) An efficient Agrobacterium-mediated genetic transformation method for foxtail millet (Setaria italica L.). Plant Cell Rep 39:511-525

Stangoulis JCR, Huynh BL, Welch RM, Choi EY, Graham RD (2007) Quantitative trait loci for phytate in rice grain and their relationship with grain micronutrient content. Euphytica 154:289-294

Suji KK, Prince KSJ, Mankhar PS, Kanagaraj P, Poornima R, Amutha K, Kavitha S, Biji KR, Gomez M, Babu RC (2012) Evaluation of rice (Oryza sativa L.) near isogenic lines with root QTLs for plant production and root traits in rainfed target populations of environment. Field Crop Res 137:89-96

Sun H, Lu J, Fan Y, Zhao Y, Kong F, Li R, Wang H, Li S (2008) Quantitative trait loci (QTLs) for quality traits related to protein and starch in wheat. Prog Nat Sci 18:825-831
Suprayogi Y, Pozniak CJ, Clarke FR, Clarke JM, Knox RE, Singh AK (2009) Identification and validation of quantitative trait loci for grain protein concentration in adapted Canadian durum wheat populations. Theor Appl Genet 119:437-448

Tian R, Jiang Gh, Shen LH, Wang LQ, He YQ (2005) Mapping quantitative trait loci underlying the cooking and eating quality of rice using a DH population. Mol Breed 15:117-124

Torres LG, Vilela de Resende MD, Azevedo CF, Fonseca E Silva F, de Oliveira EJ (2019) Genomic selection for productive traits in biparental cassava breeding populations. PLoS One 14:e0220245

Tsatsakis AM, Nawaz MA, Kouretas D et al (2017) Environmental impacts of genetically modified plants: a review. Environ Res $156: 818-833$

Umbeck PF (1992) Genetic engineering of cotton plants and lines. United States Patent 5, 159:135

van Nocker S, Gardiner SE (2014) Breeding better cultivars, faster: applications of new technologies for the rapid deployment of superior horticultural tree crops. Hortic Res 1:14022

Varshney RK, Thudi M, Roorkiwal M, He W et al (2019) Resequencing of 429 chickpea accessions from 45 countries provides insights into genome diversity, domestication and agronomic traits. Nat Genet 51:857-864

Waltz E (2016) CRISPR-edited crops free to enter market, skip regulation. Nat Biotechnol 34:582

Wang LQ, Liu WJ, Xu Y, He YQ, Luo LJ, Xing YZ, Xu CG, Zhang Q (2007) Genetic basis of 17 traits and viscosity parameters characterizing the eating and cooking quality of rice grain. Theor Appl Genet 115:463-476

Wang L, Cui F, Wang J, Jun L, Ding A, Zhao C, Li X, Feng D, Gao J, Wang H (2012) Conditional QTL mapping of protein content in wheat with respect to grain yield and its components. J Genet 91:303-312

Wang W, Mauleon R, Hu Z et al (2018) Genomic variation in 3,010 diverse accessions of Asian cultivated rice. Nature 557:43-49

Wang S, Wong D, Forrest K, Allen A et al (2014) Characterization of polyploid wheat genomic diversity using a high-density 90,000 single nucleotide polymorphism array. Plant Biotechnol J 12:787-796

Wang M, Weiberg A, Lin FM et al (2016) Bidirectional cross-kingdom RNAi and fungal uptake of external RNAs confer plant protection. Nat Plants 2:16151

Wassom JJ, Mikkelineni V, Bohn MO, Rocheford TR (2008) QTL for fatty acid composition of maize kernel oil in Illinois high oil $\times$ B73 backcross-derived lines. Crop Sci 48:69-74

Watson A, Ghosh S, Williams MJ, Cuddy WS, Simmonds J et al (2018) Speed breeding is a powerful tool to accelerate crop research and breeding. Nat Plants 4:23-29

Weckwerth W, Ghatak A, Bellaire A, Chaturvedi P, Varshney RK (2020) PANOMICS meets germplasm. Plant Biotechnol J. https ://doi.org/10.1111/pbi.13372 (published online ahead of print, 2020 Mar 12)

Woo JW, Kim J, Il Kwon S et al (2015) DNA-free genome editing in plants with preassembled CRISPR-Cas9 ribonucleoproteins. Nat Biotechnol 33:1162-1164

Worrall EA, Bravo-Cazar A, Nilon AT et al (2019) Exogenous application of RNAi-inducing double-stranded RNA inhibits aphidmediated transmission of a plant virus. Front Plant Sci 10:265

Xin W, Zhang L, Zhang W, Gao J, Yi J, Zhen X, Du M, Zhao Y, Chen L (2019) An integrated analysis of the rice transcriptome and metabolome reveals root growth regulation mechanisms in response to nitrogen availability. Int J Mol Sci 20:5893

Xu J, Yuan Y, Xu Y, Zhang G, Guo X, Wu F, Wang Q, Rong T, Pan G, Cao M, Tang Q, Gao S, Liu Y, Wang J, Lan H, Lu Y (2014) Identification of candidate genes for drought tolerance by wholegenome resequencing in maize. BMC Plant Biol 14:83 
Yang G, Dong Y, Li Y, Wang Q, Shi Q, Zhou Q (2013) Verification of QTL for grain starch content and its genetic correlation with oil content using two connected RIL populations in high-oil maize. PLoS One 8:e53770

Yang GH, Dong YB, Li YL, Wang QL, Shi QL, Zhou Q (2014a) QTL verification of grain protein content and its correlation with oil content by using connected RIL populations of high-oil maize. Genet Mol Res 13:881-894

Yang Y, Rao Y, Xu J, Shao G, Leng Y, Huang L, Wang L, Dai L, Zhang G, Hu J, Zhu L, Li C, Gao Z, Guo L, Qian Q, Zeng D (2014b) Genetic analysis of sugar-related traits in rice grain. South Afr J Bot 93:137-141

Yang Z, Li X, Zhang N, Zhang YN, Jiang HW, Gao J, Kuai BK, Ding YL, Huang XQ (2016) Detection of quantitative trait loci for kernel oil and protein concentration in a B73 and Zheng58 maize cross. Genet Mol Res. https://doi.org/10.4238/gmr.15038951

Yang D, Tang J, Yang D, Chen Y, Ali J, Mou T (2019) Improving rice blast resistance of Feng39S through molecular marker-assisted backcrossing. Rice (N Y) 12:70

Ye X, Al-Babili S, Klöti A, Zhang J, Lucca P, Beyer P, Potrykus I (2000) Engineering the provitamin A (beta-carotene) biosynthetic pathway into (carotenoid-free) rice endosperm. Science 287:303-305

Ying JZ, Shan JX, Gao JP, Zhu MZ, Shi M, Lin HX (2012) Identification of quantitative trait loci for lipid metabolism in rice seeds. Mol Plant 5:865-875

Yu J, Hu S, Wang J, Wong GK et al (2002) A draft sequence of the rice genome (Oryza sativa L. ssp. indica). Science 296:79-92

Yun BW, Kim MG, Handoyo T, Kim KM (2014) Analysis of rice grain quality-associated quantitative trait loci by using genetic mapping. Am J Plant Sci 5:1125-1132

Zetsche B, Gootenberg JS, Abudayyeh OO et al (2015) Cpf1 is a single RNA-guided endonuclease of a Class 2 CRISPR-Cas system. Cell 163:759-771

Zhang G, Liu X, Quan Z et al (2012) Genome sequence of foxtail millet (Setaria italica) provides insights into grass evolution and biofuel potential. Nat Biotechnol 30:549-554

Zhang Y, Tang J, Zhang Y, Yan J, Xiao Y, Zhang Y, Xia X, He Z (2011) QTL mapping for quantities of protein fractions in bread wheat (Triticum aestivum L.). Theor Appl Genet 122:971-987
Zhang M, Pinson SR, Tarpley L, Huang XY, Lahner B, Yakubova E, Baxter I, Guerinot ML, Salt DE (2014) Mapping and validation of quantitative trait loci associated with concentrations of 16 elements in unmilled rice grain. Theor Appl Genet 127:137-165

Zhao Q, Feng Q, Lu H et al (2018) Pan-genome analysis highlights the extent of genomic variation in cultivated and wild rice. Nat Genet 50:278-284

Zhao J, Sauvage C, Zhao J et al (2019) Meta-analysis of genome-wide association studies provides insights into genetic control of tomato flavor. Nat Commun 10:1534

Zhou G, Zhang Q, Tan C, Zhang XQ, Li C (2015) Development of genome-wide InDel markers and their integration with SSR, DArT and SNP markers in single barley map. BMC Genom 16:804

Zhou Y, Chebotarov D, Kudrna D, Llaca V, Lee S et al (2020) A platinum standard pan-genome resource that represents the population structure of Asian rice. Sci Data 7:113

Zhu Q, Zeng D, Yu S et al (2018) From golden rice to aSTARice: bioengineering astaxanthin biosynthesis in rice endosperm. Mol Plant 11:1440-1448

Zhu Q, King GJ, Liu X, Shan N, Borpatragohain P, Baten A, Wang P, Luo S, Zhou Q (2019) Identification of SNP loci and candidate genes related to four important fatty acid composition in Brassica napus using genome wide association study. PLoS One 14:e0221578

Ziyomo C, Bernardo R (2013) Drought tolerance in maize: indirect selection through secondary traits versus genome-wide selection. Crop Sci 53:1269-1275

Zsögön A, Čermák T, Naves ER et al (2018) De novo domestication of wild tomato using genome editing. Nat Biotechnol 36:1211-1216

Publisher's Note Springer Nature remains neutral with regard to jurisdictional claims in published maps and institutional affiliations. 